\title{
Transcriptome profiling of Puccinellia tenuiflora during seed germination under a long-term saline-alkali stress
}

Xiaoxue Ye', Hao Wang ${ }^{1}$, Xiuling Cao ${ }^{2}$, Xuejiao Jin², Fuqiang Cui', Yuanyuan Bu' ${ }^{1}$, Hua Liu², Wenwu Wu², Tetsuo Takano ${ }^{3}$ and Shenkui Liu ${ }^{2^{*}}$ (D)

\begin{abstract}
Background: Puccinellia tenuiflora is the most saline-alkali tolerant plant in the Songnen Plain, one of the three largest soda saline-alkali lands worldwide. Here, we investigated the physicochemical properties of saline-alkali soils from the Songnen Plain and sequenced the transcriptomes of germinated P. tenuiflora seedlings under long-term treatment (from seed soaking) with saline-alkali soil extracts.

Results: We found that the soils from Songnen Plain were reasonably rich in salts and alkali; moreover, the soils were severely deficient in nitrogen $[\mathrm{N}]$, phosphorus $[\mathrm{P}]$, potassium $[\mathrm{K}]$ and several other mineral elements. This finding demonstrated that $P$. tenuiflora can survive from not only high saline-alkali stress but also a lack of essential mineral elements. To explore the saline-alkali tolerance mechanism, transcriptional analyses of $P$. tenuiflora plants treated with water extracts from the saline-alkali soils was performed. Interestingly, unigenes involved in the uptake of $\mathrm{N}, \mathrm{P}, \mathrm{K}$ and the micronutrients were found to be significantly upregulated, which indicated the existence of an efficient nutrition-uptake system in $P$. tenuiflora. Compared with $P$. tenuiflora, the rice Oryza sativa was hypersensitive to saline-alkali stress. The results obtained using a noninvasive microtest techniques confirmed that the uptake of $\mathrm{NO}_{3}{ }^{-}$and $\mathrm{NH}_{4}{ }^{+}$and the regulatory flux of $\mathrm{Na}^{+}$and $\mathrm{H}^{+}$were significantly higher in the roots of $P$. tenuiflora than in those of $O$. sativa. In the corresponding physiological experiments, the application of additional nutrition elements significantly eliminated the sensitive symptoms of rice to saline-alkali soil extracts.
\end{abstract}

Conclusions: Our results imply that the survival of $P$. tenuiflora in saline-alkali soils is due to a combination of at least two regulatory mechanisms and the high nutrient uptake capacity of $P$. tenuiflora plays a pivotal role in its adaptation to those stress. Taken together, our results highlight the role of nutrition uptake in saline-alkali stress tolerance in plants.

Keywords: saline-alkali, Puccinellia tenuiflora, transcriptome, noninvasive microtest technique, abiotic stress, mineral elements

\section{Background}

Soil salinization is a major environmental threat to the agriculture industry worldwide and affects approximately $20 \%$ of the world's cultivated land and nearly half of all irrigated land, and the impact is becoming increasingly severe [1]. In fact, it has predicted that $30 \%$ and up to $50 \%$ of land will be lost due to salinization within the next 25 years and by 2050, respectively [2]. The Songnen

\footnotetext{
* Correspondence: shenkuiliu@nefu.edu.cn

${ }^{2}$ State Key Laboratory of Subtropical Silviculture, Zhejiang A\&F University, Lin'an, Hangzhou 311300, China

Full list of author information is available at the end of the article
}

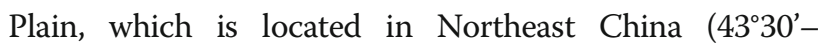
$48^{\circ} 40^{\prime} \mathrm{N}, 121^{\circ} 30^{\prime}-127^{\circ} 00^{\prime} \mathrm{E}$ ), is one of the most important grain-producing areas and serves as an important base for the combination of animal husbandry, agriculture and forestry. However, this area is severely threatened by salinization and alkalization, and a large area of arable land in this plain is being lost. The Songnen Plain is one of the world's three major soda saline-alkali lands and was formed mainly by the accumulation of sodium bicarbonate $\left(\mathrm{NaHCO}_{3}\right)$ and sodium carbonate $\left(\mathrm{Na}_{2} \mathrm{CO}_{3}\right)$ [3-6].

The type of salt in a soil is an important factor that determines soil properties. Saline soil is usually formed by the 
accumulation of neutral salts such as $\mathrm{NaCl}$ and $\mathrm{Na}_{2} \mathrm{SO}_{4}$, whereas alkaline soil is formed by the accumulation of alkaline salts such as $\mathrm{NaHCO}_{3}$ and $\mathrm{Na}_{2} \mathrm{CO}_{3}$ [7]. Soil salinization can cause oxidative stress, ion toxicity, osmotic stress and metabolic disturbance to plants and thereby affect the growth, division and survival of plant cells [8]. Under salt stress, light utilization and carbon $(\mathrm{C})$ assimilation are inhibited, which leads to an increase in reactive oxygen species (ROS) within chloroplasts and mitochondria and thereby results in oxidative stress [9]. External $\mathrm{Na}^{+}$can negatively impact intracellular $\mathrm{K}^{+}$influx. Alterations in $\mathrm{K}^{+}$ions (due to the impact of high-salinity stress) can disturb the osmotic balance and the functions of stomata and some enzymes. Concentrations of $\mathrm{Na}^{+}$ions greater than $100 \mathrm{mM}$ in soils can be cytotoxic to plants by inhibiting the activity of many important enzymes, cell division and dilatation, membrane disintegration and osmotic imbalance, all of which eventually lead to the inhibition of growth [10]. Some studies have demonstrated that saline-alkali soils are more destructive to plants than saline soils, because plants are able to endure concomitant saline and alkali (high pH) stress [11]. Based on the above-described findings, saline-alkali soils can be more damaging to crops compared with neutral-salt soils because they exhibit oxidative stress, ion toxicity, osmotic stress and high $\mathrm{pH}$, which make it difficult for most crops to grow.

To explore the molecular mechanisms used by plants to survive in the saline-alkali soils in the Songnen Plain, it is necessary to study the halophytes growing in the area. Approximately 74 halophilic seed-producing plants are found in the Songnen Plain [12]. Among these, Puccinellia tenuiflora is one of the few species that can survive under severe saline-alkali stress, and in fact, this species is usually used to improve saline-alkali soils [13]. Under experimental conditions, the growth of $P$. tenuiflora is actually stimulated at alkali $\left(\mathrm{NaHCO}_{3}\right.$ and $\mathrm{Na}_{2} \mathrm{CO}_{3}$ ) levels below $60 \mathrm{mmol} / \mathrm{L}$ alkali [14]. The root growth of $P$. tenuiflora was only slightly inhibited by exposure to $150 \mathrm{mmol} / \mathrm{L} \mathrm{Na}_{2} \mathrm{CO}_{3}$ for $24 \mathrm{~h}$ and $200 \mathrm{mmol} / \mathrm{L} \mathrm{Na}_{2} \mathrm{CO}_{3}$ for $12 \mathrm{~h}$ [15]. Surprisingly, P. tenuiflora can tolerate a maximum of $600 \mathrm{mmol} / \mathrm{L} \mathrm{NaCl}$ and $150 \mathrm{mmol} / \mathrm{L} \mathrm{NaHCO}_{3}$ [16]. Under $150 \mathrm{mmol} \mathrm{NaCl}$ or $6 \mathrm{mmol} \mathrm{NaHCO}_{3}$ treatment, wildtype Arabidopsis exhibits both chlorosis and a stunted growth phenotype and ultimately dies [17]. Glycine soja seeds can germinate in sodic soils at a pH of 9.02 and cannot survive in nutrient solutions that contain more than $50 \mathrm{mM} \mathrm{NaHCO}_{3}$ [18]. Therefore, $P$. tenuiflora is considered a pioneer plant for studying saline-alkali tolerance mechanisms.

Several studies have explored the P. tenuiflora molecular features involved in coping with saline-alkali stress. For instance, $P$. tenuiflora seedlings treated with $\mathrm{NaCl}, \mathrm{Na}_{2} \mathrm{SO}_{4}$ or both $\mathrm{NaHCO}_{3}$ and $\mathrm{Na}_{2} \mathrm{CO}_{3}$ were shown to quench ROS [19], adjust osmotic balance and maintain ion balance under saline-alkali stress $[14,20]$. cDNA libraries have been constructed from $P$. tenuiflora to analyze its gene expression profiles under $\mathrm{NaHCO}_{3}$ treatment [21, 22], and comparative proteomics has revealed several differentially expressed proteins in $P$. tenuiflora leaves in response to $\mathrm{NaCl}$ or $\mathrm{Na}_{2} \mathrm{CO}_{3}$ treatment $[15,23,24]$. Some novel salt tolerance genes in $P$. tenuiflora plants treated with $200 \mathrm{mM} \mathrm{NaCl}$ for $0,6,12,24$ and $48 \mathrm{~h}$ have been discovered [25]. These studies have provided important information for understanding the salt tolerance mechanisms in P. tenuiflora. However, most relevant studies focused on single or several salt mixture stresses, which makes it difficult to recapitulate the real situation observed in saline-alkali soils and to analyze the tolerance mechanisms underlying the comprehensive stress responses in natural saline-alkali soils.

In this study, to explore the complex factors that limit plant growth in saline-alkali soils, the physicochemical properties of saline-alkali soils from the Songnen Plain were observed. In addition, transcriptome analyses of $P$. tenuiflora plants germinated in saline-alkali soil extracts and normal soil extracts (control) were performed to reveal the tolerance mechanisms of $P$. tenuiflora adapted to this environment. A noninvasive microtest technique (NMT) was then performed to measure the $\mathrm{NO}_{3}{ }^{-}, \mathrm{NH}_{4}{ }^{+}$, $\mathrm{Na}^{+}$and $\mathrm{H}^{+}$fluxes in P. tenuiflora and Oryza sativa roots under saline-alkali stress. Multiple mineral elements were supplied to O. sativa by a chelating agent, and the physiological experiment indicated that these supplies enhanced the saline-alkali stress tolerance of rice.

\section{Results}

\section{Damage from saline-alkali soils to plants and soil} physicochemical properties

To explore the growth state under saline-alkali stress conditions, $P$. tenuiflora and the gramineous crop $O$. sativa were selected for saline-alkali tolerance analysis. First, the plants were grown in normal soil to a height of approximately 15 $\mathrm{cm}$, and images of their phenotypes were obtained during this period (Additional file 1: Figure S1 a, c). The seedlings were then watered with saline-alkali soil extracts every three days, and after one week, their phenotype was imaged. The observations revealed that $P$. tenuiflora plants grew normally, with only a few yellow leaves at 7 days after treatment (Additional file 1: Figure $\mathrm{S} 1 \mathrm{~b}$ ), whereas the leaves of $O$. sativa plants became curled and yellow within 1 day after treatment and eventually died after one week (Additional file 1: Figure S1 d). The survival of the plants was clearly severely restricted after treatment with the saline-alkali soil extracts, and $P$. tenuiflora was more adaptable to saline-alkali stress than was O. sativa.

To understand how saline-alkali soils are detrimental to plants growth, liquid extracts of saline-alkali soil from the Songnen Plain were prepared, and the physicochemical properties of the extracts were determined. The soil structure was poor with a high $\mathrm{pH}$ of 10.2, and the electrical conductivity was $6,700 \mu \mathrm{S} / \mathrm{cm}$, which was within the 
highly conductive range. In addition, the composition of saline-alkali soil extracts is more complex than that of normal soil extracts (Fig. 1a). Moreover, the saline-alkali soil extracts were subjected to overall ion measurements by an inductively coupled plasma-optical emission spectrometer (ICP-OES) and a ThermoFisher ICS-2100 instrument; the contents of 20 major elements are shown in Table 1. Compared with the normal soil extracts [26], the saline-alkali soil extracts were significantly lacking macronutrients, including $\mathrm{N}$, phosphorus $(\mathrm{P})$ and potassium $(\mathrm{K})$ (Fig. 1b), and micronutrients, including $\mathrm{Fe}, \mathrm{Zn}$, and manganese (Mn) (Fig. 1c). Because multiple macronutrients and micronutrients are necessary for plant growth, this scarcity might be a limiting factor for plant survival under saline-alkali stress.

Collectively, the physicochemical property analysis of the saline-alkali soil revealed that the high ion concentration and high $\mathrm{pH}$ caused by the presence of $\mathrm{NaHCO}_{3}$ salt limited the growth of plants and that the effects of the presence of $\mathrm{NaHCO}_{3}$ salt on the soil environment, such as the nutrient elements necessary for plants growth becoming insoluble and changes in the physicochemical properties and structure of the soil, are also important for the inhibition of plant growth in saline-alkali soils.

\section{The expression of thousands of unigenes was}

\section{significantly changed under saline-alkali stress}

We explored the responses of plants subjected to salinealkali soil stress, which greatly differ from those of plants subjected to individual salt treatments. To explore the mechanism underlying the notable adaptability of $P$. tenuiflora, transcriptome analyses of three independent biological replicates germinated in normal soil extracts and saline-alkali soil extracts were performed. We obtained $\sim 24$ million clean reads from each sample;
Table 1 lon concentrations of saline-alkali soil extracts

\begin{tabular}{llll}
\hline Element & $\mathrm{mg} / \mathrm{L}$ & Element & $\mathrm{mg} / \mathrm{L}$ \\
\hline $\mathrm{Na}$ & $1,909.2$ & $\mathrm{Al}$ & 2.63 \\
$\mathrm{~S}$ & 488.1 & $\mathrm{~K}$ & 2.5 \\
$\mathrm{Ca}$ & 44.43 & $\mathrm{Ti}$ & 0.98 \\
$\mathrm{~F}$ & 37.8 & $\mathrm{Cu}$ & 0.88 \\
$\mathrm{Cl}$ & 12.8 & $\mathrm{Mo}$ & 0.55 \\
$\mathrm{Mg}$ & 5.79 & $\mathrm{Ba}$ & 0.52 \\
$\mathrm{~B}$ & 5.22 & $\mathrm{As}$ & 0.37 \\
$\mathrm{~N}$ & 4 & $\mathrm{Mn}$ & 0.18 \\
$\mathrm{P}$ & 3.4 & $\mathrm{Ni}$ & 0.12 \\
$\mathrm{Fe}$ & 2.75 & $\mathrm{Zn}$ & 0.03 \\
\hline
\end{tabular}

detailed information on the RNA sequencing (RNA-seq) data is listed in Additional file 9: Table S1. De novo transcriptome assembly was performed by using Trinity with clean reads prepared from the control and treated samples, and a total of 42,276 unigenes were retrieved. A principal component analysis (PCA) was conducted to evaluate the reliability of the RNA-seq data (Fig. 2a). PC1 could explain $89.14 \%$ of the variability between the control and treated samples, and in contrast to the notable differences between groups, only small differences were detected within each group. These findings together demonstrated that the replicates and groups of the RNA-seq samples show high reliability. Accordingly, we obtained 3, 310 differentially expressed unigenes (DEGs: 2,196 upregulated, and 1,114 downregulated) that show significant changes in expression between the control group and the saline-alkali-treated group (Fig. 2b).

To annotate the unigenes assembled by Trinity, a Blastx search against seven databases was performed, and the results are summarized in Additional file 9: Table S3. Among
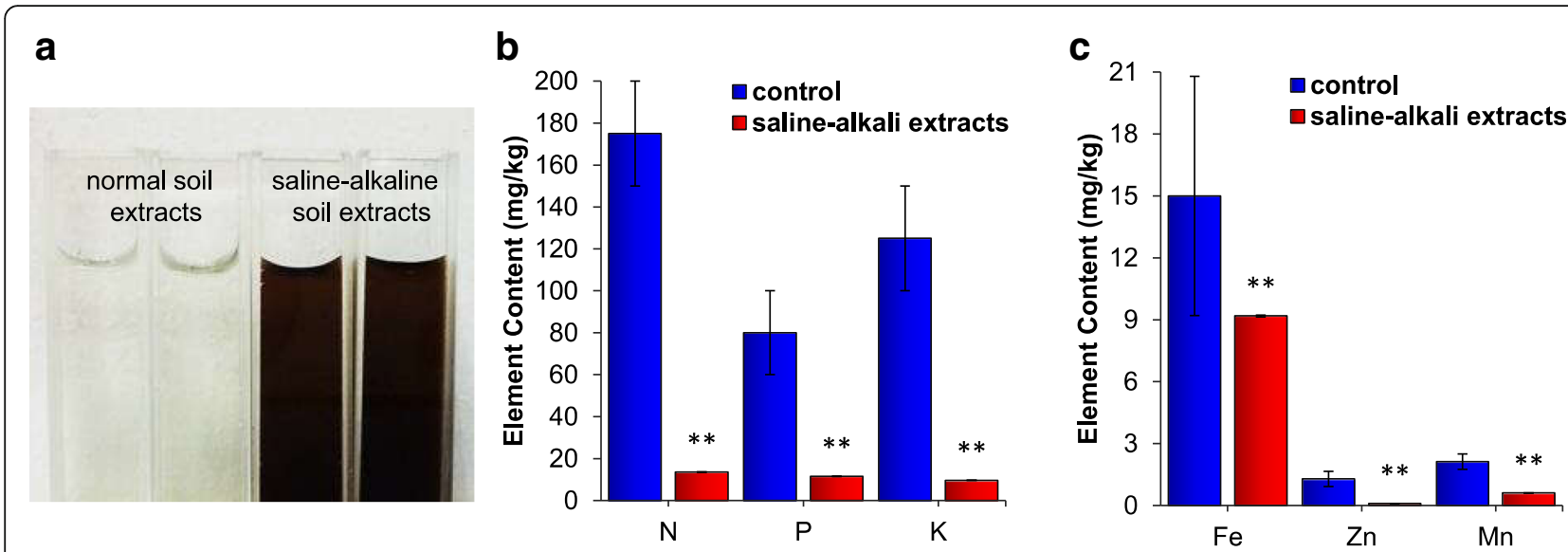

Fig. 1 a Image of normal soil extracts and saline-alkali soil extracts liquids after centrifugation at 30,000 rpm for 15 min, and passage through a $0.22-\mu \mathrm{m}$ filter membrane. $\mathbf{b}$ The contents of essential macronutrients $\mathrm{N}, \mathrm{P}$ and $\mathrm{K}$ in the saline-alkali soil extracts compared with normal soil extracts. $\mathbf{c}$ The contents of essential micronutrients $\mathrm{Fe}, \mathrm{Zn}$ and $\mathrm{Mn}$ in the saline-alkali soil extracts compared with normal soil extracts. The elements are expressed as milligrams per kilogram 

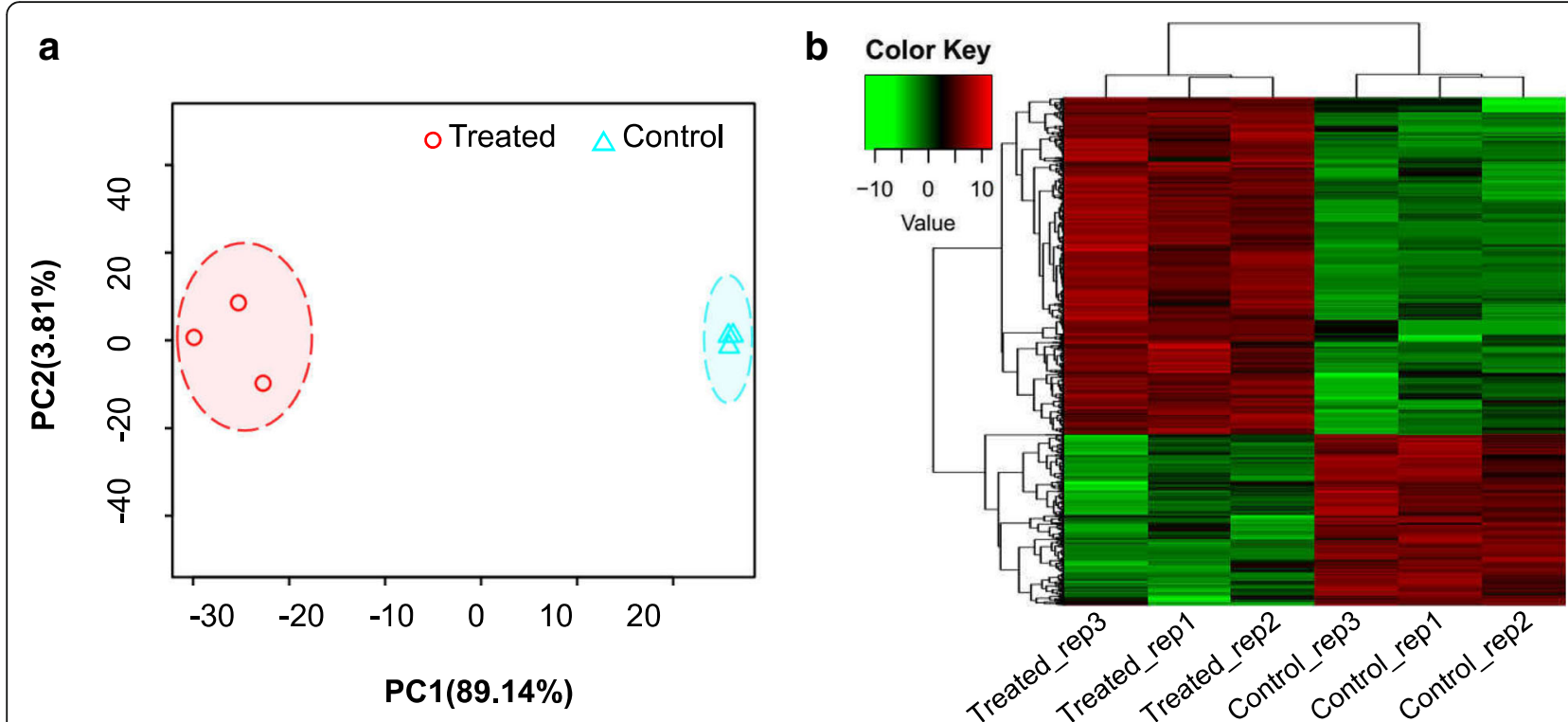

Fig. 2 Transcriptome evaluation. a PCA of three replicates of the treated and control samples. PC1 explains 89.14\% of the variability between the control and treated samples. b Heatmap of 3,310 DEGs (2,196 up regulated unigenes and 1,114 down regulated unigenes)

the assembled unigenes, 27,939 (66.08\%), 21,372 (50.55\%), 16,275 (38.49\%), 13,405 (31.71\%), 13,040 (30.84\%), 11,665 $(27.59 \%)$ and $16,829(39.80 \%)$ unigenes were successfully annotated with the Nonredundant (Nr), Gene Ontology (GO), Kyoto Encyclopedia of Genes and Genomes (KEGG), SwissProt, Poa, Pfam and Clusters of Orthologous Groups (contains both COG and KOG) databases, respectively. The similarity distribution, E-value distribution and best-hit species distribution were investigated based on the $\mathrm{Nr}$ database results (Additional file 2: Figure S2). More details for the GO, KEGG, and COG databases can be found in the Additional file 3: Figure S3, Additional file 4: Figure S4, and Additional file 5: Figure $\mathrm{S} 5$, respectively.

To better understand the function of these DEGs, GO enrichment analysis was conducted using the whole transcriptome dataset as the background. For the biological process group, "transport", "secondary metabolic process", "response to extracellular stimulus", "pigment metabolic process", "oxidation-reduction process", "organic acid metabolic process", "negative regulation of carbohydrate metabolic process" and "generation of precursor metabolites and energy" were the main enriched upregulated subgroups (Fig. 3). Moreover, "vesicle docking", "sucrose metabolic process", "response to decreased oxygen levels", "phosphate transmembrane transporter activity", "negative regulation of catalytic activity", "lipid storage", "hydrolase activity, hydrolyzing O-glycosyl compounds", "glyoxylate cycle", "endopeptidase regulator activity" and "dioxygenase activity" were the main enriched downregulated GO terms. Notably, the DEGs involved in the upregulated subgroups were associated with the GO terms "transport", "oxidation-reduction process" and "organic acid metabolic process", and these DEGs might function in the saline-alkali tolerance of $P$. tenuiflora. Heat maps based on the expression of these unigenes are shown in Additional file 6: Figure S6, and as shown, these unigenes were not only upregulated but also highly expressed. The organic acid metabolism pathway is shown in Additional file 7: Figure S7, and the red fonts represent upregulated unigenes.

To further validate the reliability of the RNA-seq analysis results, 19 DEGs were randomly selected, and their specific primers were used for real-time quantitative reverse transcription-PCR (RT-qPCR) analysis. The primer information is shown in Additional file 9: Table S2. As shown in Additional file 8: Figure S8 the expression levels measured by RT-qPCR were strongly correlated with the results obtained from the RNA-seq analysis $\left(\mathrm{R}^{2}\right.$ $=0.8073, \mathrm{P}=1.753 \mathrm{e}-07$ ), demonstrating the reliability of the RNA-seq results.

\section{DEGs were strongly associated with saline-alkali stress}

To further investigate the function of the DEGs, KEGG pathway analysis was performed. Notably, 83 upregulated and highly expressed unigenes were found to belong to the nitrate transporter (Nrt), ammonium transporter (AMT), nitrate reductase (NR), glutamate dehydrogenase (GDH), glutamine synthase (GS), glutamate synthase (GOGAT), carbonic anhydrase, ferredoxin-nitrite reductase (nirA) and cyanate lyase families, all of whose members participate in the nitrogen $(\mathrm{N})$ metabolism pathway (Fig. 4a). $\mathrm{N}$ uptake and assimilation are adversely affected by salinity stress. A heat map of the expression of these 83 unigenes is shown in Fig. 4b. The results indicate that these upregulated and highly expressed unigenes involved in $\mathrm{N}$ metabolism are modulated to allow the survival of $P$. 


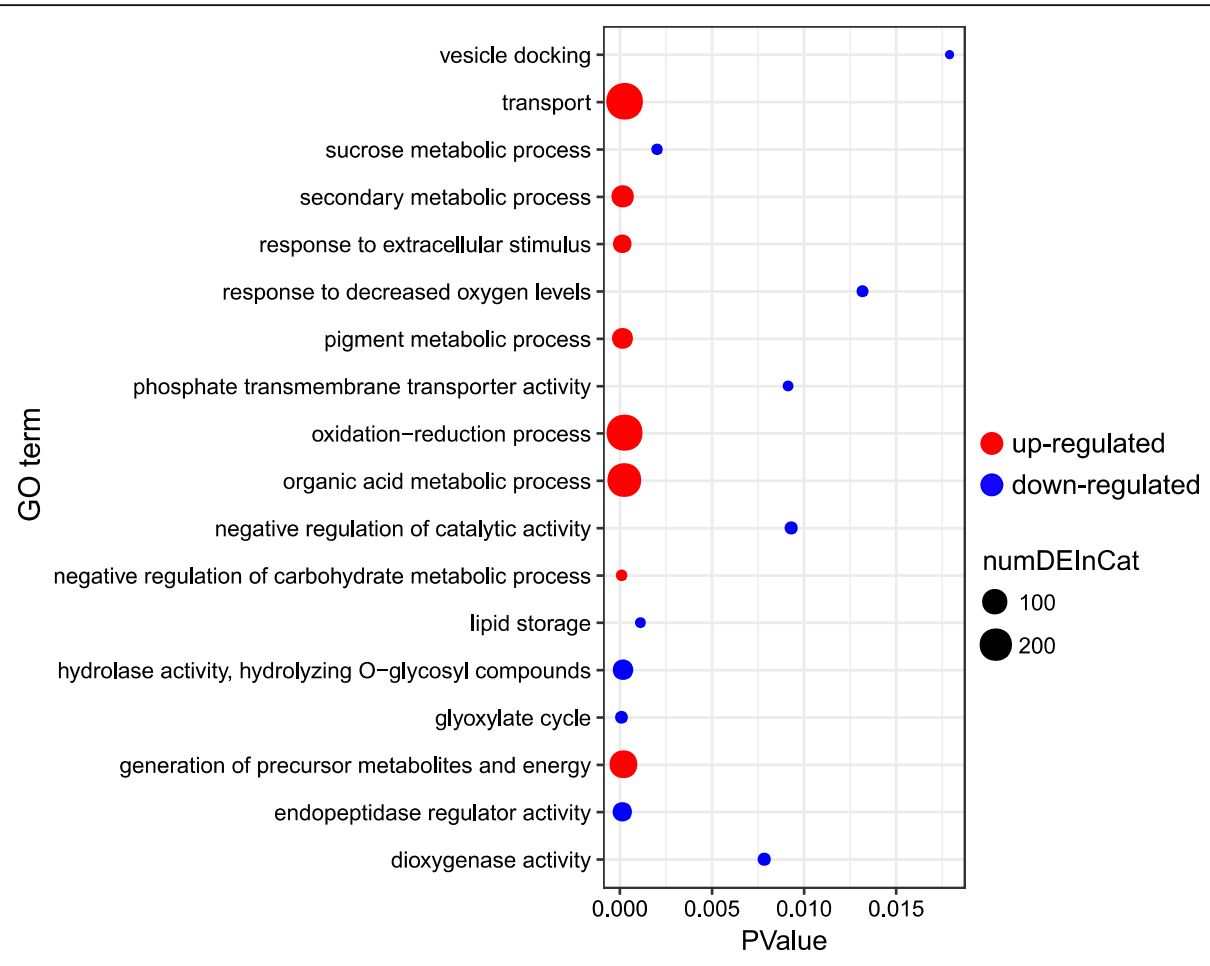

Fig. 3 Additional analysis of DEGs. GO term enrichments of the DEGs under saline-alkali conditions

\section{a}

\section{Nitrogen Metabolism}

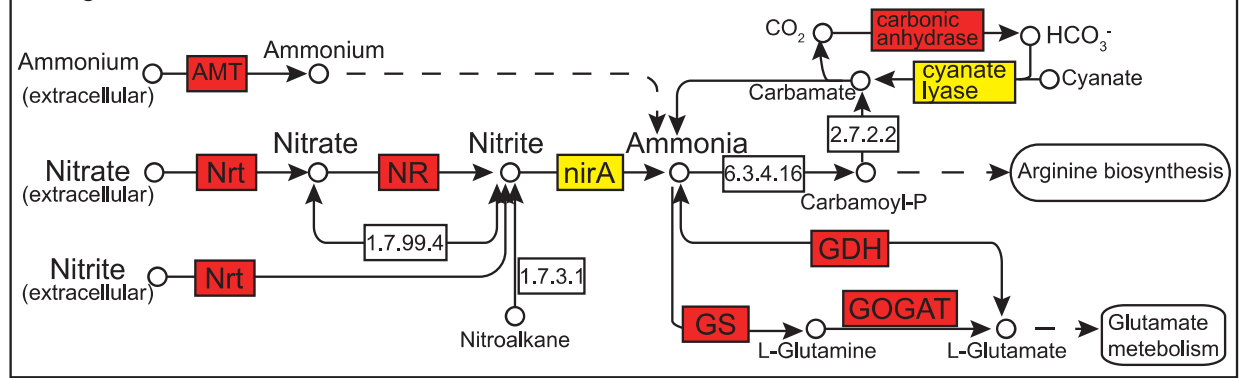

b
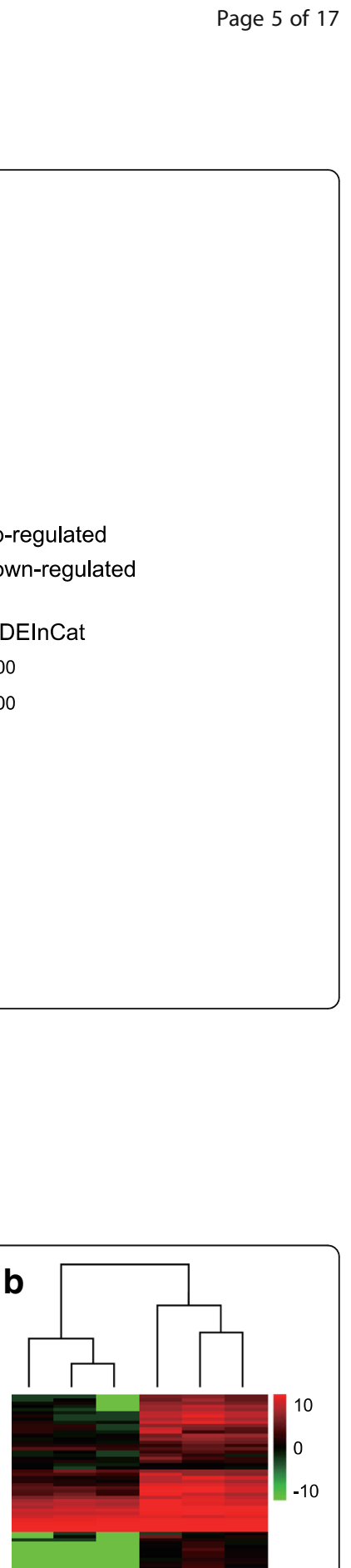
tenuiflora under the saline-alkali stress and $\mathrm{N}$ starvation conditions found in saline-alkali soils.

The uptake of $\mathrm{NO}_{3}{ }^{-}$and $\mathrm{NH}_{4}{ }^{+}$, the restriction of $\mathrm{Na}^{+}$and the flux of $\mathrm{H}^{+}$were significantly higher in the roots of $P$. tenuiflora than in those of $O$. sativa L. ssp. japonica

Because $\mathrm{N}$ metabolism-related unigenes expression in $P$. tenuiflora was markedly induced by saline-alkali stress, the $\mathrm{NO}_{3}{ }^{-}$and $\mathrm{NH}_{4}{ }^{+}$fluxes in the roots of O. sativa and P. tenuiflora were measured using an NMT to determine their ability to absorb $\mathrm{N}$ under saline-alkali stress. The dynamic changes in the $\mathrm{NO}_{3}{ }^{-}$and $\mathrm{NH}_{4}{ }^{+}$fluxes are shown in Fig. 5a and $\mathrm{c}$. The results clearly revealed that $P$. tenuiflora maintained an average $\mathrm{NO}_{3}{ }^{-}$influx of $11.28 \mathrm{pmol} / \mathrm{cm}^{2} / \mathrm{s}$, whereas O. sativa maintained an average $\mathrm{NO}_{3}{ }^{-}$efflux (rather than uptake) of $10.34 \mathrm{pmol} / \mathrm{cm}^{2} / \mathrm{s}$ (Fig. 5b). Similarly, the $\mathrm{NH}_{4}{ }^{+}$influxes in P. tenuiflora $\left(19.25 \mathrm{pmol} / \mathrm{cm}^{2} / \mathrm{s}\right)$ were significantly higher than those in $O$. sativa $\left(1.5 \mathrm{pmol} / \mathrm{cm}^{2} / \mathrm{s}\right)$, despite the presence of $\mathrm{NH}_{4}{ }^{+}$influxes in $\mathrm{O}$. sativa (Fig. $5 \mathrm{~d}$ ). These results clearly demonstrated that, after exposure to saline-alkali soil extracts, the $\mathrm{N}$ uptake rate was notably higher in $P$. tenuiflora than in $O$. sativa, which might be due to the increased expression of $\mathrm{N}$ metabolism-related unigenes.
The dynamic changes in $\mathrm{Na}^{+}$and $\mathrm{H}^{+}$fluxes in P. tenuiflora and $O$. sativa were also measured in response to saline-alkali stress (Fig. 6a and c). The statistical data revealed that, under saline-alkali stress, $O$. sativa presented an average $\mathrm{Na}^{+}$influx of $132.72 \mathrm{pmol} / \mathrm{cm}^{2} / \mathrm{s}$ (Fig. 6b). This excess $\mathrm{Na}^{+}$would induce severe root growth inhibition or even cell death. In contrast to $O$. sativa, high $\mathrm{Na}^{+}$efflux was observed in $P$. tenuiflora, which allowed this species to maintain low $\mathrm{Na}^{+}$ concentrations in its cells and thus withstand the high $\mathrm{Na}^{+}$ concentrations found in the saline-alkali soil. In addition, more $\mathrm{H}^{+}$efflux was elicited in P. tenuiflora than in O. sativa under saline-alkali stress (Fig. 6d); thus, a higher gradient was maintained across the root tissue of $P$. tenuiflora compared with that of $O$. sativa. These reasonable ionic influxes and effluxes might somewhat explain the strong saline-alkali tolerance ability of $P$. tenuiflora.

\section{Chelating agents and essential elements enhanced the saline-alkali stress tolerance of $O$. sativa}

Based on the above-mentioned results, the saline-alkali soil extracts exhibited nutrient deficiencies, and the capacity of $P$. tenuiflora to absorb mineral elements was confirmed by the RNA-seq and NMT results. In consideration of the high $\mathrm{pH}$

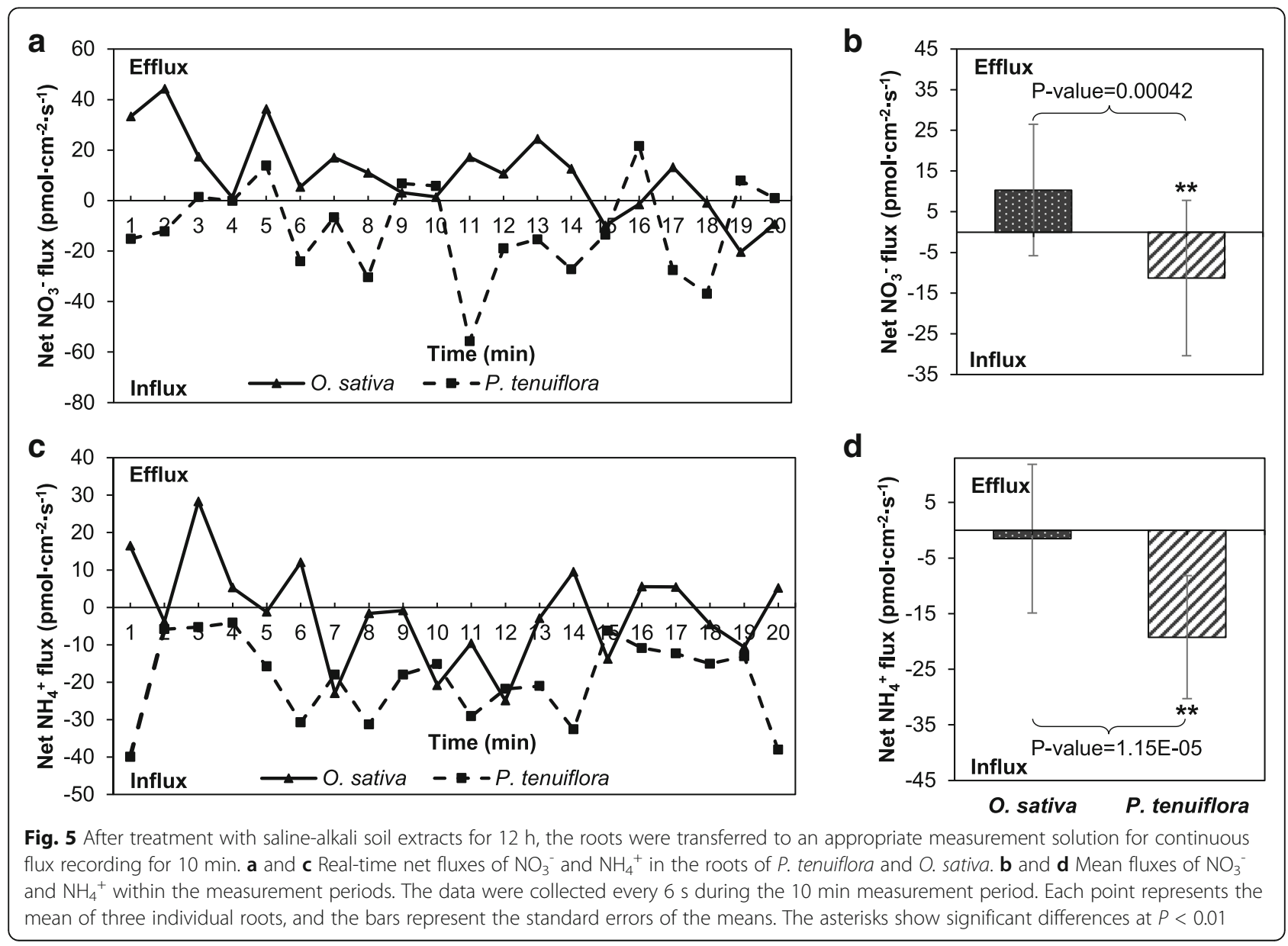



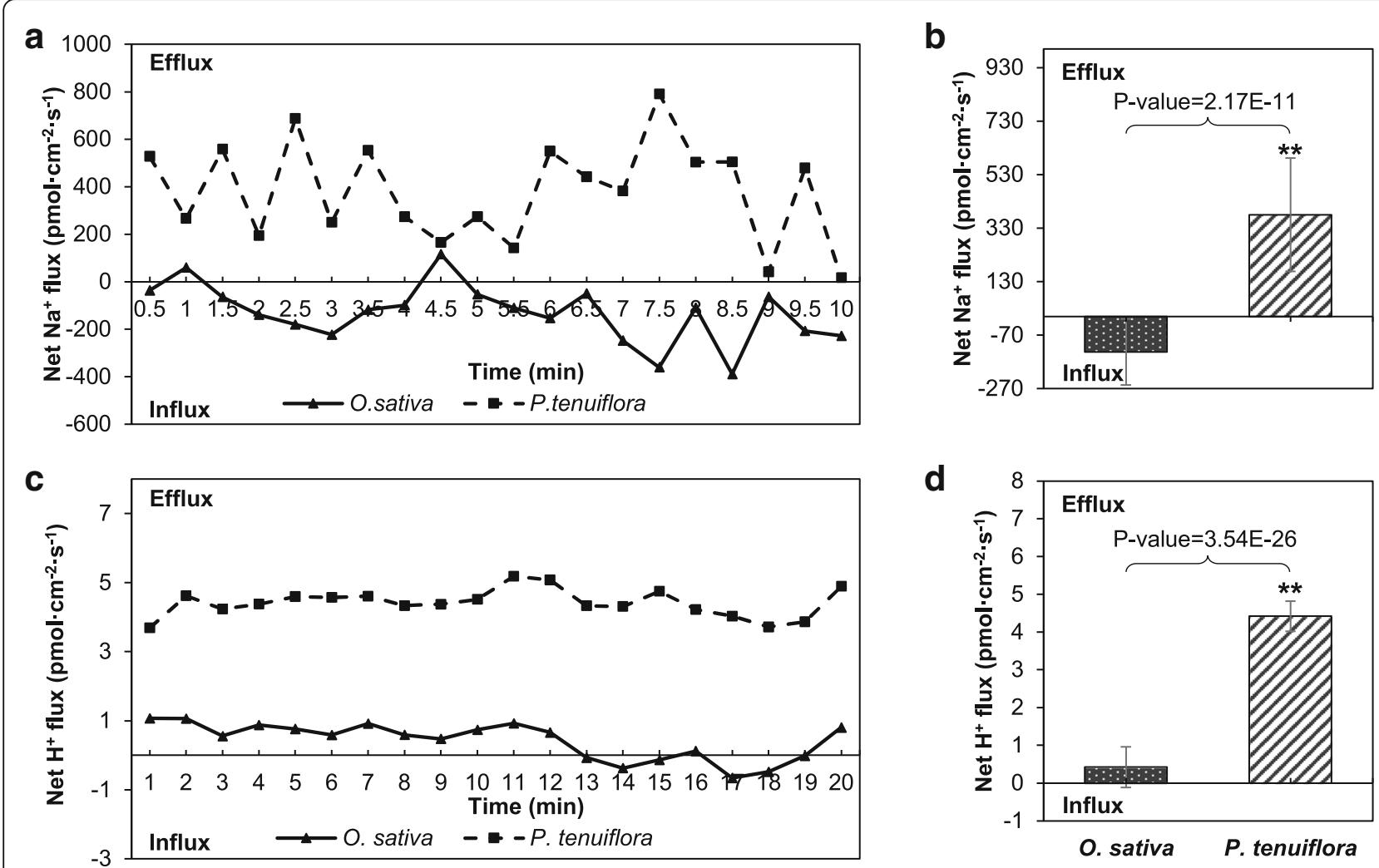

Fig. 6 After treatment with saline-alkali soil extracts for $12 \mathrm{~h}$, the roots were transferred to an appropriate measurement solution for continuous flux recording of 10 min. a and $\mathbf{c}$ Real-time net fluxes of $\mathrm{Na}^{+}$and $\mathrm{H}^{+}$in roots of $P$. tenuiflora and O. sativa. $\mathbf{b}$ and $\mathbf{d}$ Mean fluxes of $\mathrm{Na}^{+}$and $\mathrm{H}^{+}$ within the measurement periods. The data were collected every $6 \mathrm{~s}$ during the 10 min measurement period. Each point represents the mean of three individual roots, and the bars represent the standard errors of the means. The asterisks show significant differences at $P<0.01$

of the saline-alkali soil extracts, which leads to the formation of insoluble precipitates of metal cations [27, 28], we added microelements via chelating agents. EDTA is a chelating agent with a high affinity constant for the formation of metal-EDTA complexes and is deliberately added to sequester metal ions [28]. Therefore, we evaluated the growth recovery of $O$. sativa under saline-alkali stress by adding Fe(II) EDTA, Zn(II) EDTA, $\mathrm{Mn}$ (II) EDTA, $\mathrm{KNO}_{3}, \mathrm{NH}_{4} \mathrm{NO}_{3}$ and $\mathrm{KH}_{2} \mathrm{PO}_{4}$.

Two stages of $O$. sativa growth were observed: the germination stage and the seedling stage. At the germination stage, the plants in the mineral element group were clearly larger than those in the stress group (Fig. $7 \mathrm{a}$ ), and the root length, shoot height and root number were significantly increased in the mineral element group (Fig. 7b-d). The results showed that the root length in the mineral element group was maintained at an average of $9.12 \mathrm{~mm}$, whereas in the stress group, the root length was $2.38 \mathrm{~mm}$. Similarly, the shoot height in the mineral element group $(27.44 \mathrm{~mm})$ was significantly higher than that in the stress group $(19.12 \mathrm{~mm})$. An average of 4.48 roots was observed in the mineral element group, whereas an average of 2.8 roots was observed in the stress group.
The phenotype of two-week-old seedlings after 4 days of treatment is shown in Fig. 8a and b. Compared with those in the mineral element group, the leaves of the plants in the stress group were clearly curly and yellow. Although low levels of ROS play roles as signaling molecules in the response to abiotic stress, the generation of massive amounts of ROS in a cell might damage the cell membrane and lead to plant death. Therefore, we used 3,3'-diaminobenzidine $(\mathrm{DAB})$ to estimate the levels of the main ROS, $\mathrm{H}_{2} \mathrm{O}_{2}$, at the seedling stage in the two treatment groups. As shown in Fig. 8c, the plants in the mineral element group had lower levels of $\mathrm{H}_{2} \mathrm{O}_{2}$ than the plants in the saline-alkali soil extract treatment group. We also found that the relative water content (RWC) of the plants in the mineral element group was significantly higher than that of the plants in the saline-alkali soil extract treatment group (Fig. 8d). SPAD units are proportional to the chlorophyll $a+b$ content, and these values showed that the mineral elements increased the $O$. sativa chlorophyll level compared with that obtained with the extracts (Fig. 8 e and $\mathrm{f})$. Together, these results showed that the addition of mineral elements can alleviate salt damage to plants and increase the possibility of their survival. 

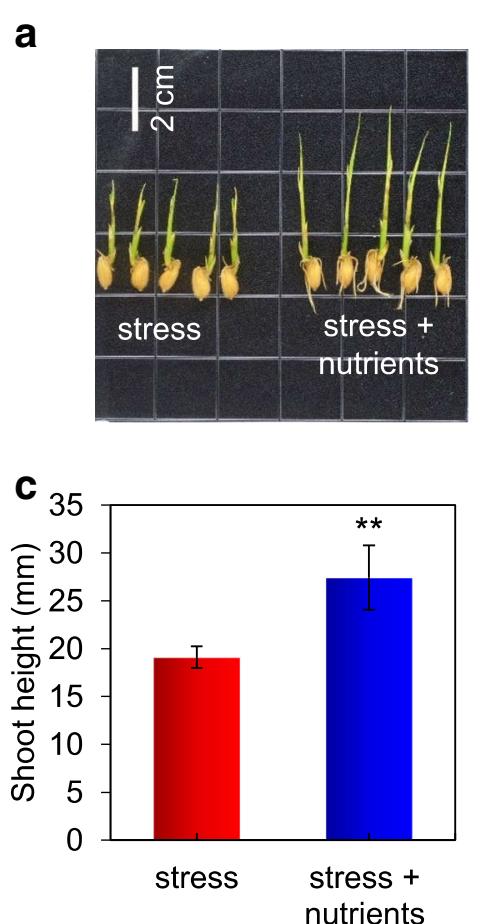

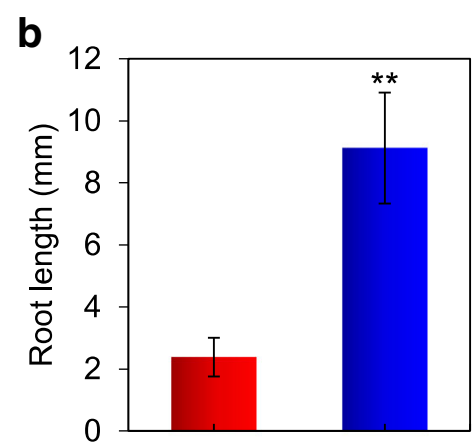

d

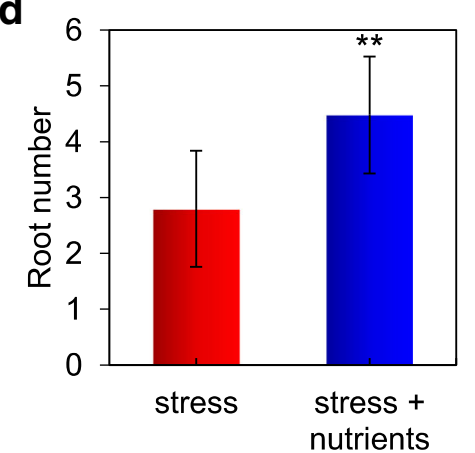

Fig. 7 a Phenotype of $O$. sativa at the germination stage in the two stress groups; the scale bars represent $2 \mathrm{~cm}$. $\mathbf{b}$ to $\mathbf{d}$ Root length, shoot height and root number of the plants in the two stress groups

\section{Discussion}

Excess ions, high pH, and element deficiency work together to limit plant growth in saline-alkali soils Saline-alkali soils consist mainly of $\mathrm{NaHCO}_{3}$ and $\mathrm{Na}_{2} \mathrm{CO}_{3}$, which cause high levels of $\mathrm{pH}$ and $\mathrm{Na}^{+}$. Thus, saline-alkali soils can cause oxidative stress, ion toxicity, osmotic stress and metabolic disturbance to plants and thereby affect the survival, growth and division of plant cells. In this study, the $\mathrm{pH}$ of the saline-alkali soil extract reached 10.2. Saline-alkali soil is lighter in color than normal soil, but its extract is dark brown. Additionally, the dark brown material remained after passage through a $0.22-\mu \mathrm{m}$ filter and high-speed centrifugation. We suspect that this color might be due to the presence of soil colloids; thus, the saline-alkali soil is sticky and shows poor permeability. The tiny colloids might also hinder the absorption of water and mineral elements by roots [6]. The content of $\mathrm{Na}^{+}$in the saline-alkali soil extract was $1,909.2 \mathrm{mg} / \mathrm{L}$ (Table 1 ), which is equal to approximately $83 \mathrm{mmol} / \mathrm{L}$, and this concentration could lead to $\mathrm{Na}$ toxicity and ion imbalance. Moreover, our ICP results indicated that the saline-alkali soil extracts were lacking various macronutrients and micronutrients (Fig. 1 ), and this lack, in combination with the high $\mathrm{pH}$ and ion toxicity, might restrict plant growth. Collectively, the analyses of the physicochemical properties of the salinealkali soil extracts revealed the detrimental and complex conditions that plants are exposed to under saline-alkali stress, and elemental deficiency was noticeable among the detected findings.

Plant adaptability under saline-alkali stress has long been investigated. However, very few studies have investigated severe mineral nutrient deficiency, which plays an important role in plant survival in alkaline soils. Under such sophisticated environmental conditions, $P$. tenuiflora exhibits a strong saline-alkali tolerance. To further study the specific metabolic pathways and regulatory mechanisms related to this saline-alkali tolerance, the transcriptomes of $P$. tenuiflora plants treated with saline-alkali soil extracts were analyzed. Although, one transcriptome analysis of $P$. tenuiflora under treatment with $20 \mathrm{mM} \mathrm{NaHCO}$ has been performed, but the low concentration used in the experiment might be not considered as a stress [14, 29]. SO, limited information is available regarding the comprehensive stress responses to excess ions, high $\mathrm{pH}$, and nutrients deficiency, which implies that saline-alkali soil extracts are more representative of natural environmental conditions than single-factor treatments.

Intracellular ion balance, osmotic adjustment, ROS scavenging and organic acid accumulation are important for the adaption of $P$. tenuiflora to saline-alkali stress Excess $\mathrm{Na}^{+}$is toxic to cell metabolism, and $\mathrm{Na}^{+} / \mathrm{H}^{+}$antiporters can transport $\mathrm{Na}^{+}$across membranes by exchanging $\mathrm{H}^{+}$for $\mathrm{Na}^{+}$[30]. Cytoplasmic $\mathrm{Na}^{+}$detoxification involves secreting $\mathrm{Na}^{+}$ions from the cytoplasm to the extracellular space or compartmentalizing them in the 

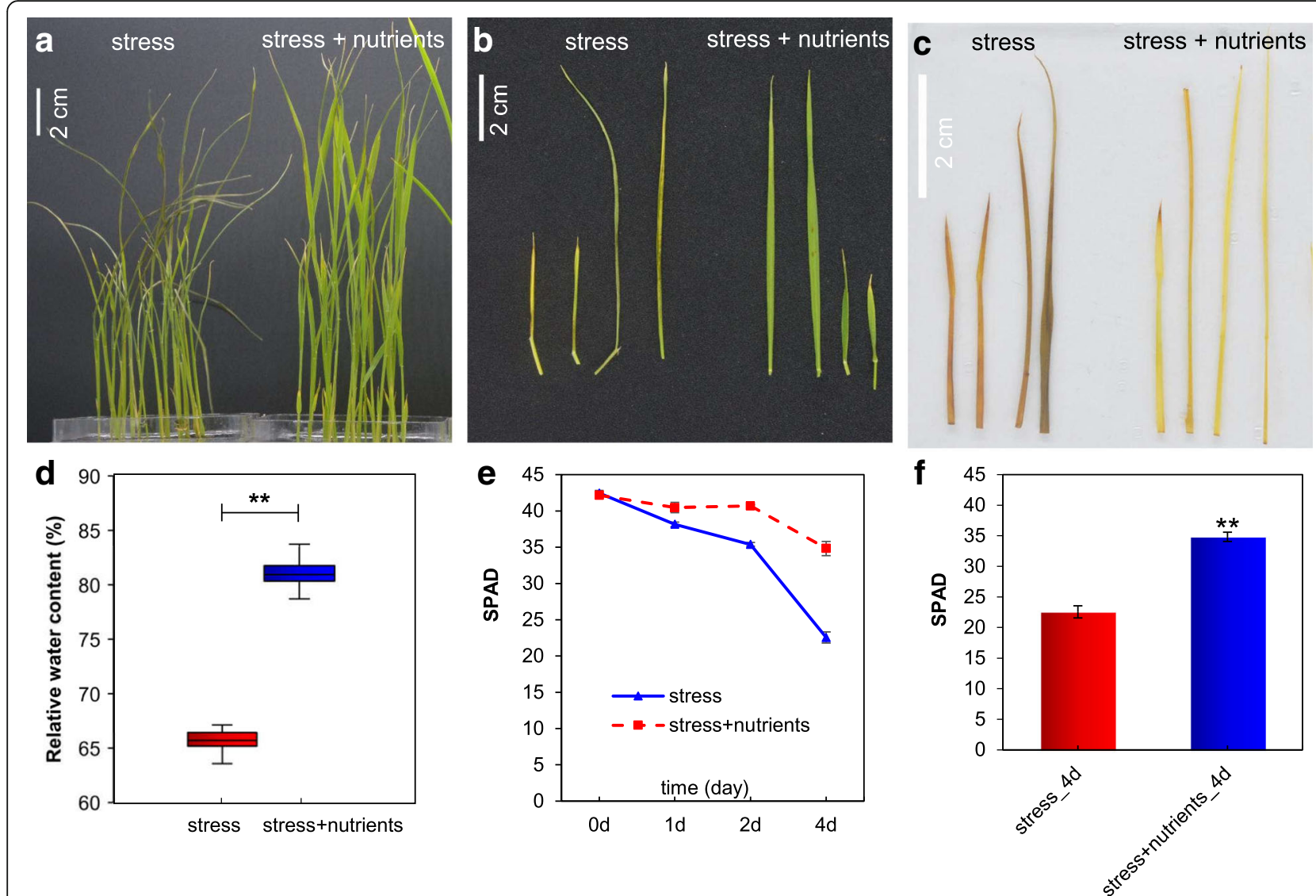

Fig. 8 a and $\mathbf{b}$ Phenotype and leaf of $O$. sativa at the seedling stage in the two stress groups; the scale bars represent $2 \mathrm{~cm}$. c Comparison of the RWC of $\mathrm{O}$. sativa between the two stress groups. d DAB staining for $\mathrm{H}_{2} \mathrm{O}_{2}$. (e) to ( $\mathrm{f}$ ) Chlorophyll level measured using a SPAD-502 meter

vacuole (Fig. 9, Unigenes brief information of Fig. 9 was shown in Additional file 9: Table S4) [19, 31]. The expression level of PutNHX obtained with the saline-alkali soil extracts treatment was significantly higher than that found with the control treatment, which indicates that PutNHX genes not only are important for $\mathrm{Na}^{+}$ion detoxification but also might function in $\mathrm{pH}$ regulation under salinealkali conditions. This result was strongly supported by our NMT results: compared with that in O. sativa roots, the influx of $\mathrm{Na}^{+}$in P. tenuiflora roots was clearly limited, and $\mathrm{H}^{+}$efflux from $P$. tenuiflora roots in alkali environments was evident (Fig. 6). The results are also in agreement with a previous study, which showed that $P$. tenuiflora leaves exposed to different concentrations of $\mathrm{Na}_{2} \mathrm{CO}_{3}$ could exude salts through their stomata or together with wax [32]. Moreover, intracellular $\mathrm{K}^{+}$and $\mathrm{Na}^{+}$ homeostasis is important for the function of many cytosolic enzymes, and the maintenance of a high $\mathrm{K}^{+}$concentration is important for $\mathrm{Na}$ tolerance [33]. The $\mathrm{CHX}$ gene product has been shown to operate as a $\mathrm{K}^{+} / \mathrm{H}^{+}$antiporter that controls $\mathrm{K}^{+}$acquisition and homeostasis [34], and the high-affinity $\mathrm{K}$ transporter HAK can mediate $\mathrm{K}^{+}$uptake by roots in rice [35]. A previous report also indicated that the maintenance of a high cytosolic $\mathrm{K}^{+} / \mathrm{Na}^{+}$ratio is important for plant salt tolerance. The upregulation of these unigenes suggested that multiple PutCHX and PutHAK transporters coordinately modulate the cytosolic $\mathrm{K}^{+} / \mathrm{Na}^{+}$ ratio and $\mathrm{pH}$ homeostasis of $P$. tenuiflora to withstand saline-alkali stress. The plasma membrane $\mathrm{H}^{+}$-ATPase, a proton pump on the plant cell membrane that pumps $\mathrm{H}^{+}$ ions to the outside environment to produce a $\mathrm{H}^{+}$transmembrane potential gradient [36], is involved in salt tolerance and is positively regulated by salt stress [37]. The expression levels of a PutPLDA unigene and three V-type proton ATPase unigenes were found to be upregulated in our study, which implies that PutPLDA increases the $\mathrm{H}^{+}$ATPase activity in P. tenuiflora. In general, the uptake of some ion, such as phosphate, is driven by the proton gradient generated by plasma membrane $\mathrm{H}^{+}$-ATPases [38] These secondary transport systems of various nutrients and ions, such as those involving PutNHX, PutHAK, PutPHT and PutAMT, need $\mathrm{H}^{+}$-ATPases to provide an electrochemical gradient driving force for transmembrane transport (Fig. 9). Consistently, our NMT results revealed a higher $\mathrm{H}^{+}$efflux in $P$. tenuiflora than in O. sativa (Fig. $6 \mathrm{c}$ and $\mathrm{d}$ ), which implies that the large proton gradient in 


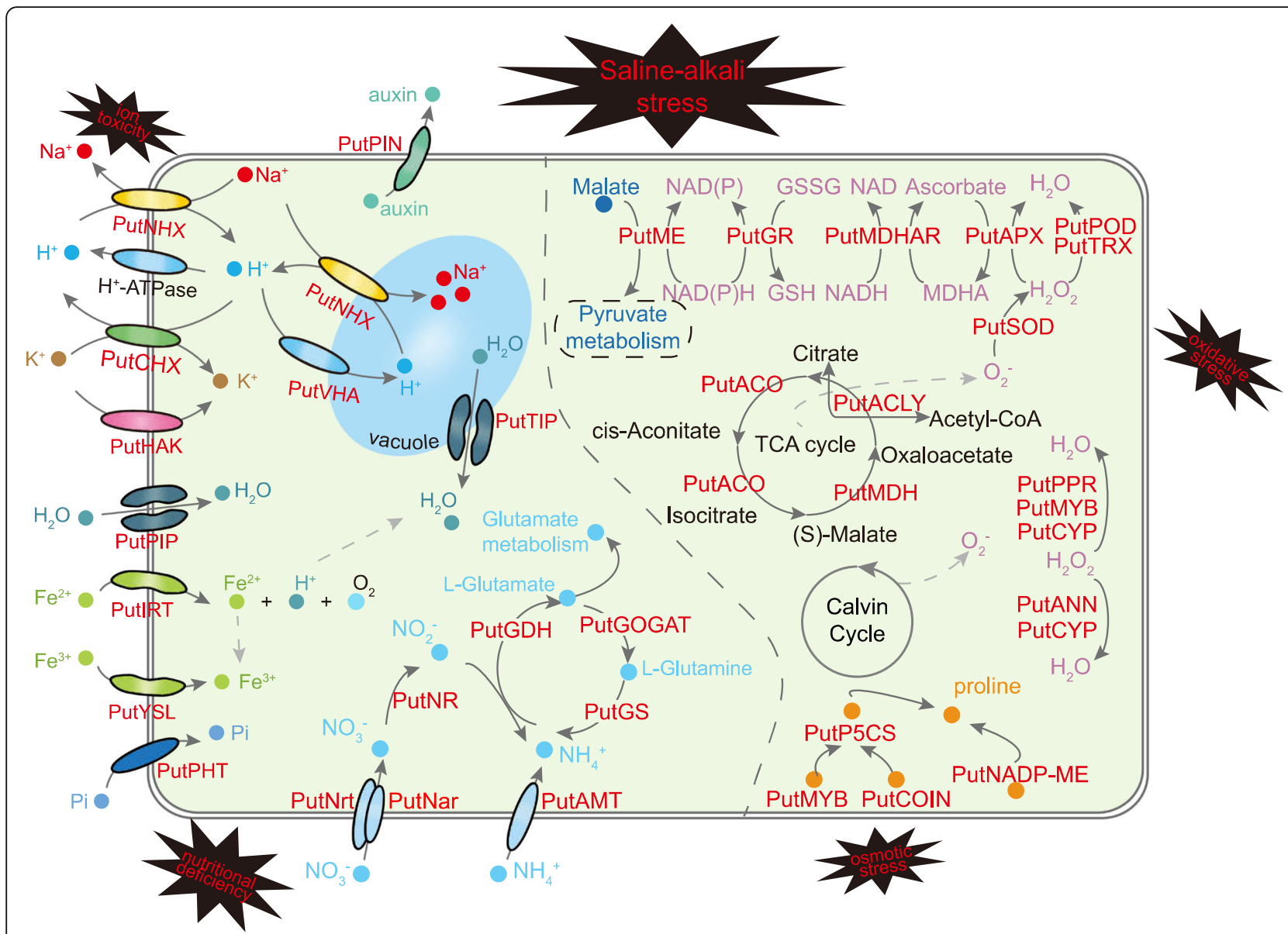

Fig. 9 Schematic presentation of systematic salt tolerance mechanism in P. tenuiflora

P. tenuiflora roots regulates the high $\mathrm{pH}$ and promotes ion transport.

Proper ion regulation protects cells by enhancing proline accumulation. A previous study revealed that the overexpression of NADP-ME2 could increase the tolerance of plants to salt and osmotic stress [39]. In addition, OsMYB91 and OsCOIN overexpressing plants, which present significantly increased proline levels, exhibit increased tolerance $[40,41]$ by regulating the expression of OsP5CS, a key enzyme involved in proline biosynthesis [42]. Therefore, the upregulation of the PutNADP-ME, PutMYB, PutCOIN and PutP5CS unigenes observed in this study would mediate the osmotic adaptation of $P$. tenuiflora to saline-alkali soils.

Upon exposure to salt stress, increased ROS levels can act as an important damage-causing agent in plants [1]. Previous studies have revealed that $P$. tenuiflora has evolved multiple antioxidant mechanisms to cope with saline-alkali stress [19]. In the present study, 272 upregulated unigenes were enriched in the oxidation-reduction process (Fig. 3), especially those encoding five critical enzymes involved in ROS scavenging: superoxide dismutase (SOD), L-ascorbate peroxidase (APX), peroxidase (POD), glutathione reductase (GR) and monodehydroascorbate reductase (MDHAR). In addition, OsCYP2 might act as a key regulator that controls the ROS levels by modulating the activities of antioxidant enzymes at the translational level [43], and OsTRXh1 can regulate apoplastic $\mathrm{ROS}$ accumulation in rice [44]. OsPPR mutants accumulate more $\mathrm{H}_{2} \mathrm{O}_{2}$ than do wild-type plants [45], and the overexpression of OsANN1 promotes SOD and catalase (CAT) activities, which regulate the $\mathrm{H}_{2} \mathrm{O}_{2}$ contents and redox homeostasis [46]. Under salt stress, OsMYB91 overexpression plants present increased tolerance with a highly enhanced ability to scavenge active oxygen [40]. Thus, upregulated unigenes were enriched in oxidation-reduction process term to reduce the damage of ROS in P. tenuiflora under saline-alkali stress.

The accumulation of citric acid in P. tenuiflora has been proved to play an important role in $\mathrm{pH}$ adjustment [47]. It has been reported that, to maintain an intracellular ionic and osmotic balance under saline or alkaline stress conditions, $P$. tenuiflora can accumulate inorganic anions and organic acids to balance the massive influx of cations [14]. In addition, the formation and 
accumulation of organic acids play an important role in $\mathrm{N}$ metabolism. Previous studies in soybean showed that the accumulation of malic acid through the phloem into the roots will increase the rate of $\mathrm{NO}_{3}{ }^{-}$uptake by the roots [48]. It was reported that, due to their high affinity for divalent and trivalent cations, citric acid and other organic acids are able to substitute $\mathrm{P}$ from insoluble compounds and thereby make these compounds more soluble and effective for plant uptake [49]. A previous study showed that under conditions of P deficiency, plants can accumulate organic acids in the roots to increase the expression of $\mathrm{P}$ transporters [50], which is an important strategy used by plants to adapt to $\mathrm{P}$ deficiency. The main form of Fe in alkaline soils is the trivalent $\mathrm{Fe}$ compound, which is difficult to dissolve in water; therefore, the amount of organic acids in plants increases to improve the ability of the protoplast membranes of root cells to reduce $\mathrm{Fe}^{3+}$, the amount of organic acids in plants increases [51, 52]. As such, understanding the relationship between mineral element uptake and utilization and organic acid metabolism is important for the rational application of fertilizers and genetic engineering to improve the utilization of fertilizer. In our study, organic acid metabolism was consistently one of the most enriched biological process GO terms (Fig. 3). More than two hundred unigenes, including those related to citric acid, malic acid and lactate metabolism, were found to be upregulated, which is similar to the results of previous studies showing that specific organic acids accumulated in alkali-resistant $P$. tenuiflora under salt stress $[14,47]$. Our RNA-seq data clearly revealed that the predominant abundance of organic acids increased the ability of $P$. tenuiflora to cope with high $\mathrm{pH}$, balance the influx of cations and improve the uptake of mineral elements (Additional file 7: Figure S7). These unigenes expression trends were consistent with previous results $[14,53]$, which demonstrate that $P$. tenuiflora might survive in saline-alkali stress by scavenging ROS and accumulating organic acids. Together, the results show that an enhanced ion balance, osmotic adjustment, ROS scavenging and organic acid accumulation coordinately promote the saline-alkali tolerance of $P$. tenuiflora plants under both saline-alkali stress and mineral nutrient deficiency (Fig. 9).

\section{Enhanced nutrient uptake is an important advantage used by $P$. tenuiflora to adapt to a saline-alkali environment, and the combination of a chelating agent with essential elements can improve the viability of $O$. sativa plants subjected to this stress}

Plant roots require a range of essential mineral elements to survive [54], and $\mathrm{N}$ is one of these essential mineral elements due to its important role in the composition of many organic compounds, such as proteins, nucleic acids, chlorophyll, enzymes, vitamins, alkaloids and hormones, which are involved in the transfer of genetic information, organelle formation, photosynthesis, respiration, and nearly all biochemical reactions [55]. The plant uptake of $\mathrm{NO}_{3}{ }^{-}$and $\mathrm{NH}_{4}{ }^{+}$is an active process mediated by Nrt (together with the high-affinity nitrate transporter-activating protein Nar [56]) and AMT, respectively. $\mathrm{N}$ assimilation involves the reduction of $\mathrm{NO}_{3}{ }^{-}$to $\mathrm{NH}_{4}{ }^{+}$, which is ultimately incorporated into amino acids through ammonia assimilation [57]. The N use efficiency (NUE) of chili pepper significantly decreases with increases in salinity conditions [58]. In contrast with previous studies on other plant species, $P$. tenuiflora can maintain higher rates of uptake and assimilation of $\mathrm{N}$, including $\mathrm{NO}_{3}{ }^{-}$and $\mathrm{NH}_{4}{ }^{+}$, compared with rice, as was confirmed by our NMT results. Furthermore, this study identified 83 upregulated and highly expressed unigenes in the $\mathrm{N}$ metabolism pathway (Fig. 4). This increased $\mathrm{N}$ metabolism might contribute to the $\mathrm{N}$ uptake of $P$. tenuiflora under saline-alkali stress combined with $\mathrm{N}$ deficiency. Additionally, the NMT was used to measure $\mathrm{N}$ uptake, and the results revealed that $P$. tenuiflora exhibited $\mathrm{NO}_{3}{ }^{-}$influx whereas $O$. sativa showed $\mathrm{NO}_{3}{ }^{-}$efflux (Fig. 5a and b). This difference in $\mathrm{N}$ uptake might be due to the expression of unigenes encoding Nrts in $P$. tenuiflora, which could lead to the different salinealkali tolerances between $P$. tenuiflora and O. sativa. Similarly, the uptake of $\mathrm{NH}_{4}{ }^{+}$in the roots of $P$. tenuiflora was greater than that in the roots of rice (Fig. $5 \mathrm{c}$ and d), which might be due to the upregulated expression of the AMT unigene (Fig. 9). The NMT results were consistent with the RNA-seq results, and both sets of results indicated that under conditions of $\mathrm{N}$ deficiency and salinity stress, $P$. tenuiflora exhibits a stronger ability to absorb $\mathrm{N}$ from its roots than O. sativa. In addition, the upregulation of unigenes related to $\mathrm{P}, \mathrm{K}, \mathrm{Fe}$ and $\mathrm{Zn}$ concurrently with that of unigenes related to $\mathrm{N}$ demonstrated that $P$. tenuiflora has developed an efficient regulatory mechanism to cope with deficiencies in essential elements, and these upregulated unigenes might have potential utility as a genetic source for engineering saline-alkali tolerance. To survive and maintain meristem activity, the expression levels of MADS-box transcription factor [59], calcium-dependent protein kinase (CDPK [60]), cysteine proteinase (EP3A [61]), and ubiquitin protein ligase (EL5 [62]) unigenes were upregulated in P. tenuiflora (Fig. 10a); the products of these unigenes are active under low $\mathrm{N}$ conditions. Our results imply that $P$. tenuiflora has its own set of mechanisms to ensure vigorous vitality under conditions of $\mathrm{N}$ deficiency. In addition, substantial changes in the expression of some unigenes in response to various mineral element deficiencies were also observed in P. tenuiflora after exposure to saline-alkali soil extracts. With respect to $\mathrm{K}$ deficiency, expression of the $\mathrm{K}$ transporter PutHAK [63], cation $/ \mathrm{H}^{+}$antiporter PutCHX [64], and CBLinteracting protein kinase PutCIPK [65], which participate 


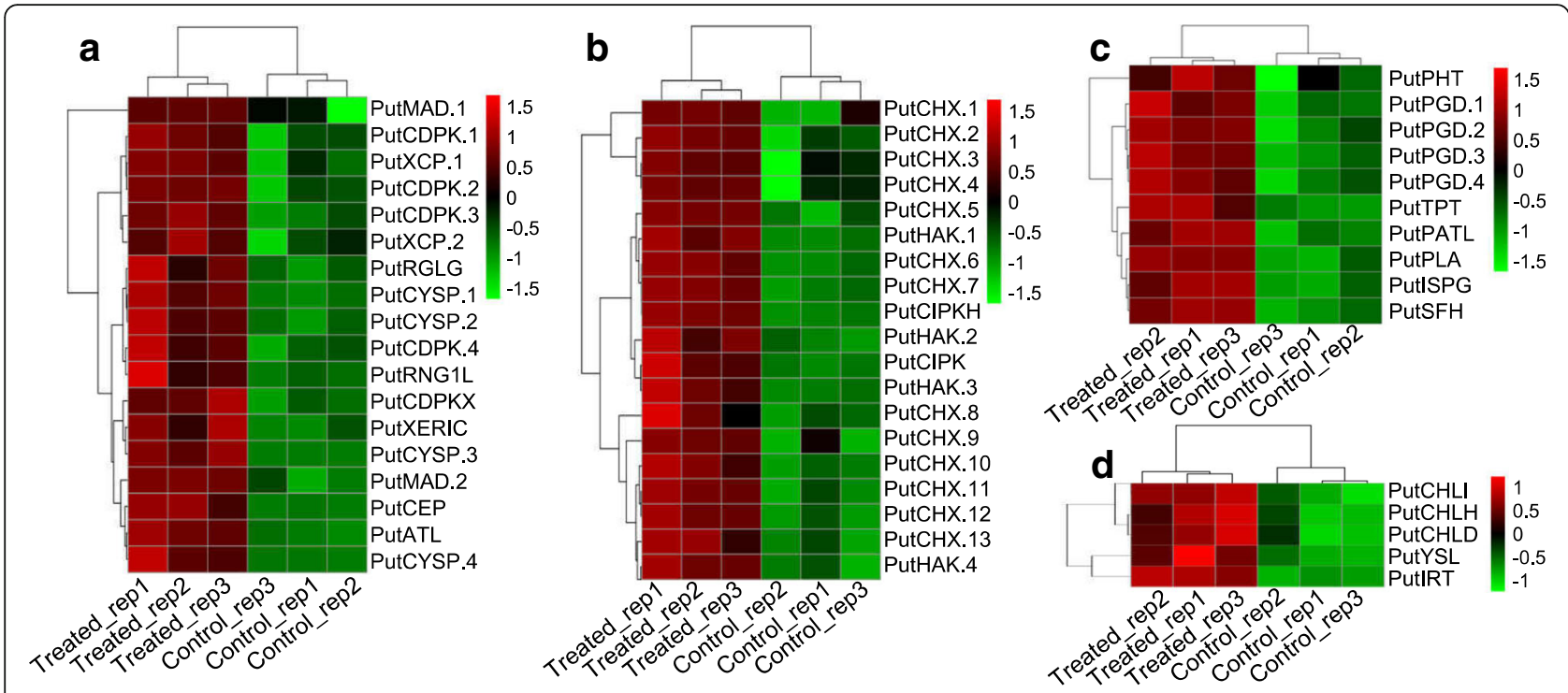

Fig. 10 a Heatmap of unigenes related to $N$ metabolism. $\mathbf{b}$ Heatmap of unigenes related to $K$ uptake. $\mathbf{c}$ Heatmap of unigenes related to $P$ uptake. $\mathbf{d}$ Heatmap of unigenes related to Fe and Zn uptake

in the competition with $\mathrm{Na}^{+}$during $\mathrm{K}$ starvation and salt stress, was upregulated significantly (Fig. 10b). The upregulation of these unigenes is likely critical for modulating $\mathrm{K}$ transport. Furthermore, the mineral nutrient $\mathrm{P}$ is also of particular importance due to the complex array of metabolic processes in which it is involved. PutPHT is a highaffinity transporter for external inorganic phosphate whose function is similar to that of PHT1-4 in Arabidopsis thaliana, which acts as a phosphate symporter under both low- and high-Pi conditions [66]. The unigenes for 6phosphogluconate dehydrogenase, a triose phosphate/ phosphate translocator, patellin-5, phospholipase A1-II, 4hydroxy-3-methylbut-2-en-1-yl diphosphate synthase and phosphatidylinositol/phosphatidylcholine transfer protein SFH (abbreviated PutPGD, PutTPT, PutPATL, PutPLA, PutSPG and PutSFH, respectively), which encode products that also participate in processes related to $\mathrm{P}$ metabolism, were annotated based on their similarity with the SwissProt database, as shown in Fig. 10c. These upregulated unigenes might function in a coordinated manner to cope with P deficiency in saline-alkali soils. Similarly, the expression of magnesium $(\mathrm{Mg})$-chelatase unigenes was also induced (Fig. 10d), which was in agreement with previous findings showing that the PutCHLH, PutCHLI and PutCHLD unigenes are required for the effective uptake of Fe under conditions of Fe deficiency [67]. Expression of the $\mathrm{Fe}\left(2^{+}\right)$transporter PutIRT [68] and the $\mathrm{Fe}\left(3^{+}\right)$metalnicotianamine transporter PutYSL [69] unigenes, which were considered to regulate $\mathrm{Fe}$ and $\mathrm{Zn}$ uptake for $P$. tenuiflora growth, was also induced. The upregulation of all these unigenes suggests that $P$. tenuiflora has evolved a comprehensive regulatory mechanism to cope with a lack of essential elements and saline-alkali stress.
A previous study revealed that dietary deficiencies of essential micronutrients such as $\mathrm{Zn}$ and Fe affect more than two billion people worldwide [70]. The diets of more than two-thirds of the global population lack one or more essential mineral elements that can be remedied by increasing the concentrations and/or bioavailability of mineral elements in produce (biofortification) [71]. During the past 3 decades, the relationship between maize grain yield (GY) formation and $\mathrm{N}$ uptake dynamics has been increasingly acknowledged in the scientific literature [72]. $\mathrm{K}$ transport in general and $\mathrm{K}$ channels in particular represent important targets and are mediators of cellular responses during different developmental stages in a plant's life cycle [73]. Moreover, in saline-alkali soils, carbonate, bicarbonate and high $\mathrm{pH}$ lead to the formation of insoluble precipitates of metal cations [27, 28], which leads to the absence of essential microelements. EDTA is a powerful complexing agent of metals and is a highly stable molecule. Synthetic chelating ligands form Fe-ligand $(\mathrm{Fe}-\mathrm{L})$ complexes in the rhizosphere, and these complexes increase the solubility of Fe and therefore its bioavailability and uptake by plants [74]. Moreover, a previous study showed that EDTA has no effect on the $\mathrm{pH}$ of the soil solution [75]. Accordingly, we added microelements via chelating agents. Due the low amounts of essential elements in the saline-alkali extracts and the upregulation of nutrient-related unigenes in resistant $P$. tenuiflora during saline-alkali stress, the nontolerant rice cultivar Nipponbare was used to explore whether supplementation with essential elements could result in plant survival. The assessment of this rice cultivar at two periods and the measurement of multiple indicators verified the important roles of mineral 
elements in saline-alkali tolerance. Thus, supplementation with mineral elements and improvement in the uptake of mineral elements represent important and potential strategies for strengthen the tolerance of crops to saline-alkali stress.

\section{Conclusions}

Our study revealed that plants in saline-alkali soils suffer from multiple constraints. In addition to conditions of excess ion toxicity, osmotic stress, oxidative stress and high $\mathrm{pH}$, deficiencies in soluble mineral elements are also a nonnegligible limiting factor. The RNA-seq and NMT results revealed the regulatory mechanism used by $P$. tenuiflora under saline-alkali stress; this mechanism involved maintenance of the intracellular ion balance, osmotic adjustment, ROS scavenging, and organic acid accumulation, particularly the uptake and assimilation of essential mineral elements (Fig. 9). On the other hand, measurements of the root length, shoot height, root number, ROS accumulation, RWC and chlorophyll content of rice at both the germination and seedling stages showed that supplementation with a chelating agent combined with essential elements can help rice survive under saline-alkali stress. These findings provide new insights into the saline-alkali tolerance mechanism of plants and the effective utilization of saline-alkali land resources in the future.

\section{Methods}

\section{Source of soils and seeds}

Soils were collected from the Alkali Soil Natural Environment Science Center of Northeast Forestry University, Anda practice base, Heilongjiang Province, Northeast China. The saline-alkali soil used for extraction was collected from the wild "barren" lands in the Songnen Plain at a depth of $0-10 \mathrm{~cm}$ depth. The normal soils used in the experiment were obtained from croplands in the Songnen Plain at $0-10 \mathrm{~cm}$ depth. Wild-type of $P$. tenuiflora seeds were provided by the Alkali Soil Natural Environment Science Center of Northeast Forestry University, Harbin, China (materials posted when needed). O. sativa L. ssp. japonica seeds were provided by the Asian Natural Environmental Science Center (ANESC) of the University of Tokyo, Japan. No specific permissions were required for these activities because sampling process did not affect any endangered or protected species.

\section{Preparation of saline-alkali soil extracts}

The uniform soil samples were passed through a sieve and then mixed separately with deionized water at a volume ratio of 1:4. The soils were thoroughly mixed, which was essential, and then incubated overnight. The resulting liquid, which represented the crude extract, was then centrifuged for $15 \mathrm{~min}$ and filtered through a $0.22-\mu \mathrm{m}$ microporous membrane. Both types of soil extracts were prepared successfully (Fig. 1a).

\section{Physicochemical properties of saline-alkali soils Determination of $\mathrm{pH}$ values and electrical conductivity}

The $\mathrm{pH}$ values of the saline-alkali soil extracts were measured using a Sartorius PB-10 instrument, which has a range of 0 to 14.00 and a resolution of \pm 0.01 . We measured the electrical conductivity of the soil extracts using a DDS-307 electrical conductivity meter (Shanghai Leici), which has a measurement range of $0.00 \mu \mathrm{S} / \mathrm{cm}$ to $100 \mathrm{mS} / \mathrm{cm}$, a basic error of $\pm 1.0 \%$ full scale (FS), and a stability of $\pm 0.33 \% \mathrm{FS} / 3 \mathrm{~h}$.

\section{Measurement of ion concentrations in the saline-alkali soil extracts}

The cation and anion concentrations in the saline-alkali soil extracts were determined using a Perkin Elmer Optima 8300 ICP-OES instrument and a ThermoFisher ICS-2100 instrument, respectively. The saline-alkali soil extracts were diluted 10-fold for detection, and the measurements were then converted to the original concentration. The analytes detected included $\mathrm{Na}, \mathrm{S}$, calcium $(\mathrm{Ca})$, fluorine $(\mathrm{F})$, chlorine $(\mathrm{Cl}), \mathrm{Mg}$, boron $(\mathrm{B}), \mathrm{N}, \mathrm{P}, \mathrm{Fe}$, aluminum $(\mathrm{Al}), \mathrm{K}$, titanium $(\mathrm{Ti})$, copper $(\mathrm{Cu})$, molybdenum (Mo), barium (Ba), arsenic (As), Mn, nickel (Ni) and $\mathrm{Zn}$. The instrument measured the intensity of light emitted by the thermally excited elements at characteristic wavelengths related to the elemental concentrations.

\section{Plant material, growth conditions and stress treatments}

The field-collected seeds were surface-sterilized with a $75 \%$ ethanol solution and then sequentially rinsed three times with sterilized distilled water, once with a $0.1 \%$ $\mathrm{NaClO}$ solution and three times with sterilized distilled water. The seeds were then sown in normal soil extract (control group) and saline-alkali soil extract (treated group) separately for germination. The greenhouse was maintained at $28{ }^{\circ} \mathrm{C}$ (day) and $22{ }^{\circ} \mathrm{C}$ (night) under a 12/ $12 \mathrm{~h}$ photoperiod. The 3-mm-high aboveground parts of $P$. tenuiflora seedlings (three replications per group) to be used for RNA extraction were rapidly washed, frozen in liquid $\mathrm{N}_{2}$ and stored at $-80{ }^{\circ} \mathrm{C}$ separately.

\section{Transcriptome sequencing, de novo assembly and functional annotation} Approximately $8 \mu \mathrm{g}$ of RNA was isolated using the TRIzol method. The quality and quantity of the RNA samples were assessed using a NanoDrop instrument and an Agilent 2100 Bioanalyzer. High-quality RNA with an RNA integrity number (RIN) $>8$ and of sufficient quantity was used for construction of the sequencing library. The cDNA libraries were sequenced on an Illumina HiSeq 2000 platform to generate 150 bp paired-end 
Table 2 Elements Composition of the multi nutrient solution

\begin{tabular}{lll}
\hline Component & Relative molecular mass & Concentration $(\mathrm{mmol} / \mathrm{L})$ \\
\hline $\mathrm{KNO}_{3}$ & 101.1 & 469.83 \\
$\mathrm{NH}_{4} \mathrm{NO}_{3}$ & 80.04 & 515.37 \\
$\mathrm{KH}_{2} \mathrm{PO}_{4}$ & 136.1 & 31.23 \\
EDTA $-\mathrm{Mn}$ & 389.1 & 2.49 \\
EDTA $-\mathrm{Fe}$ & 367.2 & 2.50 \\
EDTA $-\mathrm{Zn}$ & 471.6 & 0.75 \\
\hline
\end{tabular}

reads. Trimmomatic [76] was used to remove the Illumina adapter contamination and for trimming the reads and clipping the low-quality bases, and at least $8 \mathrm{~Gb}$ of clean reads were obtained. Kraken software [77] was further used to delete the reads from bacteria. The clean reads were subsequently de novo assembled using Trinity software [78], and the constructed "genes" were referred to as unigenes in this study.

The unigene sequences were aligned to the Nr, Swiss-Prot, COG and Pfam databases using Blastx with an E-value of 1e-5. To obtain a high confidence of gene annotations, we constructed a database named Poa, which comprised all currently annotated Gramineae plant proteins. GO annotation was obtained using the $R$ package GOseq [79], and visualization was performed by WEGO [80] software. The unigene sequences were also aligned to the KEGG [81] pathway database using the KEGG Automatic Annotation Server (KAAS) [82]. RNAMMER [83] was used for rRNA prediction, and unigenes marked as rRNA were removed.

\section{Identification of DEGs}

The unigene expression levels of both the control group and the treatment group were calculated. An analysis of the DEGs between the two groups was performed using the $\mathrm{R}$ packages DEseq2 [84], edgeR [85] and voom [86]. We defined DEGs as those that had a false discovery rate (FDR) $\leq 0.01$ and an absolute value of log2-fold change $\geq 1$ obtained from at least two of the above-mentioned packages. GO enrichment analysis of the DEGs was performed using ClueGO [87].

\section{RT-qPCR analysis}

RT-qPCR was performed to validate the gene expression results obtained from the RNA-seq analysis. First, cDNA was reverse-transcribed from $1 \mu \mathrm{g}$ of total RNA for each sample using a High-Capacity cDNA Reverse Transcription Kit. The gene-specific primers used in this analysis (Additional file 9: Table S2) were designed using Primer-Blast (NCBI) software [88]; the PCR product length was maintained between 150 bp and $300 \mathrm{bp}$, and the primer purification method involved iPAG. The $P$. tenuiflora tubulin gene was used as an internal reference in the RT-qPCR analysis. The $20 \mu \mathrm{l}$ PCR mixture used was composed of $1 \mu \mathrm{l}$ of cDNA, $0.8 \mu \mathrm{l}$ of the specific primers, $10 \mu \mathrm{l}$ of SYBR Premix DimerEraser, and $8.2 \mu \mathrm{l}$ of
$\mathrm{ddH}_{2} \mathrm{O}$. All the reactions were performed using default parameters, and the specificity of the reactions was verified through melting curve analysis. The real-time PCR analysis incorporated the results of three biological and three technical replicates.

\section{Analysis of the ion fluxes in P. tenuiflora and O. sativa roots using the NMT}

The net $\mathrm{NO}_{3}{ }^{-}, \mathrm{NH}_{4}{ }^{+}, \mathrm{Na}^{+}$and $\mathrm{H}^{+}$fluxes within P. tenuiflora and $O$. sativa root meristematic regions were measured at the YoungerUSA Xuyue (Beijing) BioFunction Institute by using NMTs (NMT100 Series, YoungerUSA, LLC, Amherst, MA 01002, USA; Xuyue (Beijing) Sci. \& Tech. Co., Ltd., Beijing, China) and imfluxes V2.0 (YoungerUSA, LLC, Amherst, MA 01002, USA) software. The NMT is capable of noninvasively measuring the real-time flux of various ions by simultaneously integrating and coordinating different voltage signal collections, motion control, and image capture.

To observe the ion influx or efflux within P. tenuiflora and $O$. sativa roots, the plants were treated with salinealkali soil extracts for $12 \mathrm{~h}$. Net $\mathrm{NO}_{3}{ }^{-}, \mathrm{NH}_{4}{ }^{+}, \mathrm{Na}^{+}$and $\mathrm{H}^{+}$fluxes in the meristematic zone of the roots were monitored, and a steady flux was recorded for $20 \mathrm{~min}$. The test solution for $\mathrm{NO}_{3}{ }^{-}$consisted of $0.1 \mathrm{mM} \mathrm{CaCl}_{2}$, $0.1 \mathrm{mM} \mathrm{KNO}{ }_{3}$ and $0.3 \mathrm{mM} 2$-( $\mathrm{N}$-morpholino) ethanesulfonic acid (MES), and the test solution for $\mathrm{NH}_{4}{ }^{+}$consisted of $0.1 \mathrm{mM} \mathrm{CaCl}, 0.1 \mathrm{mM} \mathrm{NH}_{4} \mathrm{Cl}$ and $0.3 \mathrm{mM}$ MES. The test solution for $\mathrm{Na}^{+}$consisted of $0.1 \mathrm{mM}$ $\mathrm{CaCl}, 0.1 \mathrm{mM} \mathrm{KCl}, 0.5 \mathrm{mM} \mathrm{NaCl}$ and $0.3 \mathrm{mM}$ MES, and the test solution for $\mathrm{H}^{+}$consisted of $0.1 \mathrm{mM} \mathrm{CaCl}, 0.1$ $\mathrm{mM} \mathrm{KCl}$ and $0.3 \mathrm{mM}$ MES. The $\mathrm{pH}$ of each test solution was 6 , and each experiment was repeated four times. The differences in microvolts $(\Delta \mu \mathrm{V})$ were then exported as raw data before they were imported and converted into the net $\mathrm{Na}^{+}$(the same as $\mathrm{H}^{+}, \mathrm{NO}_{3}{ }^{-}, \mathrm{NH}_{4}{ }^{+}$) fluxes by using JCal V3.3 (a free Microsoft Excel spreadsheet; youngerusa.com or xbi.org) [89].

\section{Supply of chelating agents combined with essential elements to $O$. sativa under saline-alkali conditions}

The seeds used to investigate the germination stage were sterilized with $0.1 \% \mathrm{NaClO}$ for $30 \mathrm{~min}$ and then washed with distilled water. The seeds were then soaked in distilled water for $12 \mathrm{~h}$ and pregerminated in Petri dishes that contained three layers of moistened filter paper for $24 \mathrm{~h}$. Upon emergence, $\sim 30$ seeds were separately placed in saline-alkali soil extracts that contained or did not contain essential elements (Fe(II) EDTA, Zn(II) EDTA, $\mathrm{Mn}(\mathrm{II})$ EDTA, $\mathrm{KNO}_{3}, \mathrm{NH}_{4} \mathrm{NO}_{3}$, and $\mathrm{KH}_{2} \mathrm{PO}_{4}$ ) for germination. The components of the elements in the nutrient solution are shown in Table 2. To control the consistency of the treatment conditions, the $\mathrm{pH}$ of the solution was adjusted to 9.5 , and $1 \mathrm{ml}$ was dissolved in $100 \mathrm{ml}$ of soil extracts. Considering the poor resistance 
of $O$. sativa, we diluted the soil extract once. The shoot height, root length and root number of 20 randomly selected seedlings were manually measured on day 10 .

The seeds used to investigate the seedling stage were washed and pregerminated using the same protocol used in the germination investigation. The $O$. sativa plants were grown in 1/8-strength Murashige and Skoog (MS) solution, which was renewed every 3 days. Two-week-old seedlings were transferred to saline-alkali soil extracts that contained or did not contain essential elements, and the seedlings were then allowed to grow for $72 \mathrm{~h}$. The RWC was recorded by weighing the individual seedlings. DAB staining was also performed for measurement of the $\mathrm{H}_{2} \mathrm{O}_{2}$ level according to previously described methods [90]. The SPAD-502 meter (Konica Minolta Sensing, Osaka, Japan) is a hand-held device that is widely used for rapid, accurate and nondestructive measurements of leaf chlorophyll concentrations [91]. Ten independent SPAD values were recorded per treatment using different plants.

\section{Additional files}

Additional file 1: Figure S1. (a) and (b) Phenotypes of $P$. tenuiflora and O. sativa seedlings in normal soil. (c) and (d) Seedlings watered with saline-alkali soil extract for one week. (e) and (f) Scanning electron microscope micrographs of saline-alkali soil extracts. (TIF 12908 kb)

Additional file 2: Figure S2. BLAST results from the Nr database. (a) Similarity distribution. (b) Best-hit species classification. (c) E-value distribution. (PDF $120 \mathrm{~kb}$ )

Additional file 3: Figure S3. GO classifications of assembled unigenes from $P$. tenuiflora obtained using Blast2GO. The unigenes were annotated in three main categories: cellular component, molecular function and biological process. The $x$-axis indicates the subcategories, and the $y$-axis indicates the number of unigenes. (PDF $273 \mathrm{~kb}$ )

Additional file 4: Figure S4. KEGG pathways of assembled unigenes from $P$. tenuiflora. The $x$-axis indicates the categories, and the $y$-axis indicates the number of unigenes. (PDF $189 \mathrm{~kb}$ )

Additional file 5: Figure S5. COG classifications of assembled unigenes from $P$. tenuiflora. Of the 42,276 de novo-assembled unigenes, 16,829 were annotated and separated into 23 categories. (PDF $141 \mathrm{~kb}$ )

Additional file 6: Figure S6. Additional analysis of DEGs. (a) Heatmap of 278 transport unigenes that share a significantly upregulated pattern. (b) Heatmap of 272 oxidation-reduction process unigenes that share a significantly upregulated pattern. (c) Heatmap of 271 organic acid metabolic process unigenes that share a significantly upregulated pattern. (PDF $162 \mathrm{~kb}$ )

Additional file 7: Figure S7. Organic acid metabolism under salinealkali conditions; the red font indicates the upregulated unigenes. (PDF $107 \mathrm{~kb})$

Additional file 8: Figure S8. Correlation analysis of 19 randomly selected DEGs based on the qRT-PCR and RNA-seq data. Pearson correlation coefficients are shown $\left(R^{2}=0.8073\right)(P<0.001)$. (PDF $\left.78 \mathrm{~kb}\right)$

Additional file 9: Table S1. Summary of Illumina transcriptome sequencing for $P$. tenuiflora. Table S2. Primers information. Table S3. Functional annotation of the unigenes of $P$. tenuiflora. Table S4.

Unigenes in salt tolerance mechanisms schematic in P. tenuiflora. (XLSX 13 kb)

\section{Abbreviations}

AMT: ammonium transporter; CDPK: calcium-dependent protein kinase; COG: Clusters of Orthologous Groups; DAB: 3,3'-diaminobenzidine; DEGs: differentially expressed genes; EDS: energy dispersive spectroscopy;
EL5: ubiquitin protein ligase; EP3A: cysteine proteinase; GDH: glutamate dehydrogenase; GO: Gene Ontology; GOGAT: glutamate synthase; GS: glutamine synthase; ICP-OES: inductively coupled plasma-optical emission spectrometer; KEGG: Kyoto Encyclopedia of Genes and Genomes; Nar: highaffinity nitrate transporter-activating protein; nirA: ferredoxin-nitrite reductase; NMT: noninvasive microtest techniques; NR: nitrate reductase;

Nr: nonredundant; Nrt: nitrate transporter; P. tenuiflora: Puccinellia tenuiflora; PCA: principal component analysis; ROS: reactive oxygen species; RTqPCR: real-time quantitative reverse transcription-PCR; RWC: relative water content

\section{Acknowledgements \\ Not applicable.}

\section{Authors' contributions}

SL contributed to the conception and design of this study. XY performed the transcriptome analyses and physiology experiment. HW collected salinealkali soils and performed RNA extraction. WW designed the transcriptome analyses pipeline. FC, and $\mathrm{HL}$ designed the physiology experiments and data analysis. YB performed the RT-qPCR experiment. XY, XC, XJ and TT drafted the manuscript. All authors read and approved the final manuscript.

\section{Funding}

This work was supported by the Zhejiang Science and Technology Major Program on Agricultural New Variety Breeding (Grant No. 2016C02056-1 to $\mathrm{SL})$, the Program for Changjiang Scholars, Innovative Research Team in University (PCSIRT) (IRT_17R99) and the Special Fund for Forest Scientific Research in the Public Welfare (201404220) awarded to Shenkui Liu. The funders had no role in the study design.

\section{Availability of data and materials}

All the sequencing data generated in this study have been deposited in the Sequence Read Archive (SRA) database under accession number PRJNA491308.

Ethics approval and consent to participate Not applicable.

\section{Consent for publication}

Not applicable.

\section{Competing interests}

The authors declare that they have no competing interests.

\section{Author details}

${ }^{1}$ Key Laboratory of Saline-Alkali Vegetation Ecology Restoration in Oil Field (SAVER), Ministry of Education, Alkali Soil Natural Environmental Science Center (ASNESC), Northeast Forestry University, Harbin 150040, China. ${ }^{2}$ State Key Laboratory of Subtropical Silviculture, Zhejiang A\&F University, Lin'an, Hangzhou 311300, China. ${ }^{3}$ Asian Natural Environmental Science Center (ANESC), the University of Tokyo, Nishitokyo-shi, Tokyo 188-0002, Japan.

Received: 13 November 2018 Accepted: 29 May 2019

Published online: 17 July 2019

\section{References}

1. Zhu J. Plant salt tolerance. Trends Plant Sci. 2001;6(2):1360-85.

2. Wang W, Vinocur B, Altman A. Plant responses to drought, salinity and extreme temperatures: towards genetic engineering for stress tolerance. Planta. 2003;218(1):1-14

3. Li X, Li Q, Wang Z, Liu X. A Research on Characteristics and Rational Exploitation of Soda Saline Land in the Western Songnen Plain. Research of Agricultural Modernization (In Chinese). 2002;23(5):361-4.

4. Wang L, Seki K, Miyazaki T, Ishihama Y. The causes of soil alkalinization in the Songnen Plain of Northeast China. Paddy Water Environ. 2009;7(3):259-70.

5. Li J, Zheng H. The Amendment of Saline Alkali Grasslands in Songnen Plain and Their Bio-ecological Mechanism. Beijing: Science Press. 1997:5-8.

6. Wang H, Takano T, Liu S. Screening and Evaluation of Saline-Alkaline Tolerant Germplasm of Rice (Oryza sativa L.) in Soda Saline-Alkali Soil. Agronomy. 2018;8(10):205. 
7. Ge Y, Li J. A preliminary study on the effects of halophytes on salt accumulation and desalination in the soils of Songnen plain. Northeast China Acta Prataculturae Sinica. 1990;1:70-6.

8. Mahajan S, Pandey GK. NarendraTuteja. Calcium- and salt-stress signaling in plants: Shedding light on SOS pathway. Arch Biochem Biophys. 2008;471(2): 146-58.

9. Asada K. The water-water cycle in chloroplasts: scavenging of active oxygens and dissipation of excess photons. Annu Rev Plant Physiol Plant Mol Biol. 1999;50:601-39.

10. Tuteja N. Mechanisms of high salinity tolerance in plants. Methods Enzymol. 2007:428:419-38

11. Guo R, Yang Z, Li F, Yan C, Zhong X, Liu Q, Xia X, Li H, Zhao L. Comparative metabolic responses and adaptive strategies of wheat (Triticum aestivum) to salt and alkali stress. BMC Plant Biol. 2015;15(1):170

12. Jian-dong L, Yun-feiy Y. Combinatorial structures of plant species in saline communities in the Songnen Plains of China. Acta Pratacul Sin. 2004;13(1):32-8.

13. Chonghao $L$, Xuanfeng $Z$, Kuiyi $Z$, Juxin $Y$. Vegetation of the Songnen Plain. Scientia geographica sinica. 1982;2(2):170-8

14. Guo LQ, Shi DC, Wang DL. The Key Physiological Response to Alkali Stress by the Alkali-Resistant Halophyte Puccinellia tenuiflora is the Accumulation of Large Quantities of Organic Acids and into the Rhyzosphere. J Agron Crop Sci. 2010;196(2):123.

15. Zhao Q, Suo J, Chen S, Jin Y, Ma X, Yin Z, Zhang Y, Wang T, Luo J, Jin W, et al. Na2CO3-responsive mechanisms in halophyte Puccinellia tenuiflora roots revealed by physiological and proteomic analyses. Sci Rep. 2016;6(1).

16. Zhang X, Wei L, Wang Z, Wang T. Physiological and Molecular Features of Puccinellia tenuiflora Tolerating Salt and Alkaline-Salt Stress. J Integr Plant Biol. 2013;55(3):262-76.

17. Guan Q, Ma H, Wang Z, Wang Z, Bu Q, Liu S. A rice LSD1-like-type ZFP gene OsLOL5 enhances saline-alkaline tolerance in transgenic Arabidopsis thaliana yeast and rice. BMC Genomics. 2016;17(1):1-11.

18. Ying G, Yang M, Zhu D, Dong T, Wang W, Tan S, Liu C, Zou P. Research on responses of wild soybean to alkaline stress. Pratacultural Science. 2009; 26(2):47-52

19. Wang $X$, Yang R, Wang B, Liu G, Yang C, Cheng Y. Functional characterization of a plasma membrane $\mathrm{Na}+/ \mathrm{H}+$ antiporter from alkali grass (Puccinellia tenuiflora). Mol Biol Rep. 2011;38(7):4813-22.

20. Wang C, Zhang J, Liu X, Li Z, Wu G, Cai J, Flowers TJ, Wang S. Puccinellia tenuiflora maintains a low $\mathrm{Na}+$ level under salinity by limiting unidirectional $\mathrm{Na}+$ influx resulting in a high selectivity for $\mathrm{K}+$ over $\mathrm{Na}+$. Plant Cell Environ. 2009;32(5):486-96.

21. Wang Y, Yang C, Liu G, Jiang J. Development of a CDNA microarray to identify gene expression of Puccinellia tenuiflora under saline-alkali stress. Plant Physiol Biochem. 2007;45(8):567-76.

22. Wang Y, Chu Y, Liu G, Wang M, Jiang J, Hou Y, Qu G, Yang C. Identification of expressed sequence tags in an alkali grass (Puccinellia tenuiflora) CDNA library. J Plant Physiol. 2007:164(1):78-89.

23. Yu J, Chen S, Zhao Q, Wang T, Yang C, Diaz C, Sun G, Dai S. Physiological and Proteomic Analysis of Salinity Tolerance in Puccinellia tenuiflora. J Proteome Res. 2011;10(9):3852-70.

24. Yu J, Chen S, Wang T, Sun G, Dai S. Comparative Proteomic Analysis of Puccinellia tenuiflora Leaves under Na2CO3 Stress. Int J Mol Sci. 2013;14(1):1740-62.

25. Li Y, Takano T, Liu S. Discovery and Characterization of Two Novel SaltTolerance Genes in Puccinellia tenuiflora. Int J Mol Sci. 2014;15(9):16469-83.

26. Sun X. Pedology: China Forestry Publishing House; 2005.

27. Oliva J, De Pablo J, Cortina J, Cama J, Ayora C. The use of Apatite $I^{\mathrm{TM}}$ to remove divalent metal ions zinc(II), lead(II), manganese(II) and iron(II) from water in passive treatment systems: Column experiments. J Hazard Mater. 2010;184(1-3):364-74

28. Oviedo C, Rodríguez J. EDTA: THE CHELATING AGENT UNDER ENVIRONMENTAL SCRUTINY. Química Nova. 2003:26(6):901-5.

29. Kobayashi S, Satone H, Tan E, Kurokochi H, Asakawa S, Liu S, Takano T. Transcriptional Responses of a Bicarbonate-Tolerant Monocot, Puccinellia tenuiflora, and a Related Bicarbonate-Sensitive Species, Poa annua, to NaHCO3 Stress. Int J Mol Sci. 2015;16(1):496-509.

30. Ma Y, Augé RM, Dong C, Cheng ZM. Increased salt tolerance with overexpression of cation/proton antiporter 1 genes: a meta-analysis. Plant Biotechnol J. 2017;15(2):162-73.

31. Shi H, Ishitani M, Kim C, Zhu JK. The Arabidopsis thaliana salt tolerance gene SOS1 encodes a putative Na+/H+ antiporter. Proc Natl Acad Sci U S A. 2000; 97(12):6896-901.
32. Guorong S, Yongzhen P, Hongbo S, Liye C, Xining Z, Haiyan M, Wenzhong C, Cunxu W. Does Puccinelia tenuiflora have the ability of salt exudation? Colloids Surf B Biointerfaces. 2005;46(4):197-203.

33. Rubio F, Gassmann W, Schroeder Jl. Sodium-Driven Potassium Uptake by the Plant Potassium Transporter HKT1 and Mutations Conferring Salt Tolerance. Science. 1995;270(5242):1660-3.

34. Cellier F, Conéjéro G, Ricaud L, Luu DT, Lepetit M, Gosti F, Casse F. Characterization of AtCHX17, a member of the cation/H+ exchangers, $\mathrm{CHX}$ family, from Arabidopsis thaliana suggests a role in $\mathrm{K}+$ homeostasis. Plant J. 2004;39(6):834-46.

35. Banuelos MA. Inventory and Functional Characterization of the HAK Potassium Transporters of Rice. Plant Physiol. 2002;130(2):784-95.

36. Duby $G$, Boutry M. The plant plasma membrane proton pump ATPase: a highly regulated P-type ATPase with multiple physiological roles. Pflügers Archiv - European Journal of Physiology. 2009:457(3):645-55.

37. Shen $P$, Wang $R$, Jing W, Zhang W. Rice Phospholipase Da is involved in Salt Tolerance by the Mediation of H+-ATPase Activity and Transcription. J Integr Plant Biol. 2011;53(4):289-99.

38. Muchhal US, Pardo JM, Raghothama KG. Phosphate transporters from the higher plant Arabidopsis thaliana. P Natl Acad Sci Usa. 1996;93(19): 10519-23.

39. Liu S, Cheng Y, Zhang X, Guan Q, Nishiuchi S, Hase K, Takano T. Expression of an NADP-malic enzyme gene in rice (Oryza sativa. $L$ ) is induced by environmental stresses; over-expression of the gene in Arabidopsis confers salt and osmotic stress tolerance. Plant Mol Biol. 2007;64(1-2):49-58.

40. Zhu N, Cheng S, Liu X, Du H, Dai M, Zhou D, Yang W, Zhao Y. The R2R3type MYB gene OSMYB91 has a function in coordinating plant growth and salt stress tolerance in rice. Plant Sci. 2015;236:146-56.

41. Liu K, Wang L, Xu Y, Chen N, Ma Q, Li F, Chong K. Overexpression of OsCOIN, a putative cold inducible zinc finger protein, increased tolerance to chilling, salt and drought, and enhanced proline level in rice. Planta. 2007; 226(4):1007-16.

42. Zhang Z, Li F, Li D, Zhang H, Huang R. Expression of ethylene response factor JERF1 in rice improves tolerance to drought. Planta. 2010;232(3): 765-74

43. Ruan SL, Ma HS, Wang SH, Fu YP, Xin Y, Liu WZ, Wang F, Tong JX, Wang SZ, Chen $\mathrm{HZ}$. Proteomic identification of OsCYP2, a rice cyclophilin that confers salt tolerance in rice (Oryza sativa L.) seedlings when overexpressed. BMC Plant Biol. 2011;11:34.

44. Zhang CJ, Zhao BC, Ge WN, Zhang YF, Song Y, Sun DY, Guo Y. An Apoplastic H-Type Thioredoxin Is Involved in the Stress Response through Regulation of the Apoplastic Reactive Oxygen Species in Rice. Plant Physiol. 2011;157(4):1884-99.

45. Tan J, Tan Z, Wu F, Sheng P, Heng Y, Wang X, Ren Y, Wang J, Guo X, Zhang $X$, et al. A Novel Chloroplast-Localized Pentatricopeptide Repeat Protein Involved in Splicing Affects Chloroplast Development and Abiotic Stress Response in Rice. Mol Plant. 2014;7(8):1329-49.

46. Qiao B, Zhang Q, Liu D, Wang H, Yin J, Wang R, He M, Cui M, Shang Z, Wang $D$, et al. A calcium-binding protein, rice annexin OsANN1, enhances heat stress tolerance by modulating the production of H2O2. J Exp Bot. 2015:66(19):5853-66.

47. De-Cheng S, Shang-Jun Y, Guo-Hui Y, Ke-Fu Z. Citric acid accumulation in an alkali-tolerant plant Puccinellia. Acta Botanica Sinica. 2002:44(5):537-40.

48. Touraine B, Muller B, Grignon C. Effect of Phloem-Translocated Malate on N03- Uptake by Roots of Intact Soybean Plants. Plant Physiol. 1992;99(3): 1118-23.

49. Hoffland E, Findenegg G, Nelemans J. Solubilization of rock phosphate by rape. Plant and Soil. 1989;113(2):155-60.

50. Neumann G, Mheld VR. Root excretion of carboxylic acids and protons in phosphorus-deficient plants. Plant and Soil. 1999:211:121-30.

51. AbadíaEmail J, López-Millán A, Rombolà A, Abadía A. Organic acids and Fe deficiency: a review. Plant and Soil. 2002:241(1):75-86.

52. Lindsay WL, Schwab AP. The chemistry of iron and its availability to plants. Plant Nutr. 1982:5(4-7):821-40.

53. HERNÁNDEZ JA, JIMÉNEZ A, MULLINEAUX P, SEVILLA F. Tolerance of pea (Pisum sativum L.) to long-term salt stress is associated with induction of antioxidant defences. Plant Cell Environ. 2001;23(8):853-62.

54. Schachtman DP, Reid RJ, Ayling SM. Phosphorus Uptake by Plants: From Soil to Cell. Plant Physiol. 1998;116(2):447-53.

55. Krapp A. Plant nitrogen assimilation and its regulation: a complex puzzle with missing pieces. Curr Opin Plant Biol. 2015;25:115-22. 
56. Zhou J, Fernández E, Galván A, Miller AJ. A high affinity nitrate transport system from Chlamydomonas requires two gene products. FEBS Lett. 2000; 466(2-3):225-7.

57. Goel P, Singh AK. Abiotic Stresses Downregulate Key Genes Involved in Nitrogen Uptake and Assimilation in Brassica juncea L. PLoS One. 2015; 10(11):e143645.

58. Huez-López MA, Ulery AL, Samani Z, Picchioni G, Flynn RP. Response of chile pepper (Capsicum annuum L.) to salt stress and organic and inorganic nitrogen sources: II. nitrogen and water use efficiencies, and salt tolerance. Trop Subtrop Agroecosyst. 2011;14(3):765-6.

59. Yu C, Su S, Xu Y, Zhao Y, Yan A, Huang L, Ali I, Gan Y. The Effects of Fluctuations in the Nutrient Supply on the Expression of Five Members of the AGL17 Clade of MADS-Box Genes in Rice. PLoS One. 2014:9(8):e105597.

60. Asano T, Wakayama M, Aoki N, Komatsu S, Ichikawa H, Hirochika H, Ohsugi R. Overexpression of a calcium-dependent protein kinase gene enhance growth of rice under low-nitrogen conditions. Plant Biotechnol. 2010;27:369-73.

61. Ho SL, Tong WF, Yu SM. Multiple mode regulation of a cysteine proteinase gene expression in rice. Plant Physiol. 2000;122(1):57-66.

62. Mochizuki S, Jikumaru Y, Nakamura H, Koiwai H, Sasaki K. Ubiquitin ligase EL5 maintains the viability of root meristems by influencing cytokininmediated nitrogen effects in rice. J Exp Bot. 2014;65(9):2307-18.

63. Yang T, Zhang S, Hu Y, Wu F, Hu Q, Chen G, Cai J, Wu T, Moran N, Yu L, et al. The Role of a Potassium Transporter OsHAK5 in Potassium Acquisition and Transport from Roots to Shoots in Rice at Low Potassium Supply Levels. Plant Physiol. 2014;166(2):945-59.

64. Chanroj S, Lu Y, Padmanaban S, Nanatani K, Uozumi N, Rao R, Sze H. PlantSpecific Cation/H+ Exchanger 17 and Its Homologs Are Endomembrane K+ Transporters with Roles in Protein Sorting. J Biol Chem. 2011;286(39):33931-41.

65. Li J, Long Y, Qi GN, Li J, Xu ZJ, Wu WH, Wang Y. The Os-AKT1 Channel Is Critical for K+ Uptake in Rice Roots and Is Modulated by the Rice CBL1CIPK23 Complex. Plant Cell. 2014;26(8):3387-402.

66. Shin H, Shin H, Dewbre GR, Harrison MJ. Phosphate transport in Arabidopsis: Pht 1;1 and Pht1;4 play a major role in phosphate acquisition from both low- and high-phosphate environments. Plant J. 2004;39(4):629-42.

67. Ogo Y, Itai RN, Nakanishi H, Kobayashi T, Takahashi M, Mori S, Nishizawa NK. The rice bHLH protein OsIRO2 is an essential regulator of the genes involved in Fe uptake under Fe-deficient conditions. Plant J. 2007;51(3):366-77.

68. Bughio N, Yamaguchi $\mathrm{H}$, Nishizawa N, Nakanishi H, Mori S. Cloning an ironregulated metal transporter from rice. J Exp Bot. 2002;53(374):1677-82.

69. Lee S, Chiecko JC, Kim SA, Walker EL, Lee Y, Guerinot ML, An G. Disruption of OsYSL15 Leads to Iron Inefficiency in Rice Plants. Plant Physiol. 2009; 150(2):786-800.

70. Velu G, Ortiz-Monasterio I, Cakmak I, Hao Y, Singh RP. Biofortification strategies to increase grain zinc and iron concentrations in wheat. J Cereal Sci. 2014:59(3):365-72.

71. White PJ, Broadley MR. Biofortification of crops with seven mineral elements often lacking in human diets - iron, zinc, copper, calcium, magnesium, selenium and iodine. New Phytol. 2008;182(1):49-84.

72. Ciampitti IA, Vyn TJ. Physiological perspectives of changes over time in maize yield dependency on nitrogen uptake and associated nitrogen efficiencies: A review. Field Crop Res. 2012;133:48-67.

73. Anschütz U, Becker D, Shabala S. Going beyond nutrition: Regulation of potassium homoeostasis as a common denominator of plant adaptive responses to environment. J Plant Physiol. 2014;171(9):670-87.

74. Hasegawa H, Rahman MM, Kadohashi K, Takasugi Y, Tate Y, Maki T, Rahman MA. Significance of the concentration of chelating ligands on Fe3+solubility, bioavailability, and uptake in rice plant. Plant Physiol Biochem. 2012;58:205-11.

75. Wu LH, Luo YM, Christie P, Wong MH. Effects of EDTA and low molecular weight organic acids on soil solution properties of a heavy metal polluted soil. Chemosphere. 2003;50(6):819-22

76. Bolger AM, Lohse M, Usadel B. Trimmomatic: a flexible trimmer for Illumina sequence data. Bioinformatics. 2014;30(15):2114-20.

77. Davis MPA, van Dongen S, Abreu-Goodger C, Bartonicek N, Enright AJ. Kraken: A set of tools for quality control and analysis of high-throughput sequence data. Methods. 2013;63(1):41-9.

78. Grabherr MG, Haas BJ, Yassour M, Levin JZ, Thompson DA, Amit I, Adiconis X, Fan L, Raychowdhury R, Zeng Q, et al. Full-length transcriptome assembly from RNA-Seq data without a reference genome. Nat Biotechnol. 2011;29(7):644-52.

79. Young MD, Wakefield MJ, Smyth GK, Oshlack A. Gene ontology analysis for RNA-seq: accounting for selection bias. 2010;11(2):R14.
80. Ye J, Fang L, Zheng H, Zhang Y, Chen J, Zhang Z, Wang J, Li S, Li R, Bolund L, et al. WEGO: a web tool for plotting GO annotations. Nucleic Acids Res. 2006;34(Web Server):W293-7.

81. Kanehisa M, Furumichi M, Tanabe M, Sato Y, Morishima K. KEGG: new perspectives on genomes, pathways, diseases and drugs. Nucleic Acids Res. 2017:45(D1):D353-61.

82. Moriya Y, Itoh M, Okuda S, Yoshizawa AC, Kanehisa M. KAAS: an automatic genome annotation and pathway reconstruction server. Nucleic Acids Res. 2007;35(Web Server):W182-5.

83. Lagesen $\mathrm{K}$, Hallin P, Rodland EA, Staerfeldt HH, Rognes T, Ussery DW. RNAmmer: consistent and rapid annotation of ribosomal RNA genes. Nucleic Acids Res. 2007;35(9):3100-8.

84. Love Ml, Huber W, Anders S. Moderated estimation of fold change and dispersion for RNA-Seq data with DESeq2. Genome Biol. 2014;15(12):550

85. Robinson MD, McCarthy DJ, Smyth GK. edgeR: a Bioconductor package for differential expression analysis of digital gene expression data. Bioinformatics. 2009;26(1):139-40.

86. Law CW, Chen Y, Shi W, Smyth GK. voom: Precision weights unlock linear model analysis tools for RNA-seq read counts. Genome Biol. 2014;15(2):R29.

87. Shannon P, Markiel A, Ozier O, Baliga NS, Wang JT, Ramage D, Amin N, Schwikowski B, Ideker T. Cytoscape: a software environment for integrated models of biomolecular interaction networks. Genome Res. 2003;13(11): 2498-504.

88. Ye J, Coulouris G, Zaretskaya I, Cutcutache I, Rozen S, Madden TL. PrimerBLAST: a tool to design target-specific primers for polymerase chain reaction. BMC Bioinformatics. 2012;13:134

89. Bai L, Ma X, Zhang G, Song S, Zhou Y, Gao L, Miao Y, Song CP. A ReceptorLike Kinase Mediates Ammonium Homeostasis and Is Important for the Polar Growth of Root Hairs in Arabidopsis. Plant Cell. 2014;26(4):1497-511.

90. Christensen HT, Zhang Z, Wei Y, Collinge DB. Subcellular localization of $\mathrm{H} 2 \mathrm{O} 2$ in plants. $\mathrm{H} 2 \mathrm{O} 2$ accumulation in papillae and hypersensitive response during the barley-powdery mildew interaction. Plant J. 1997;11(6):1187-94.

91. Ling Q, Huang W, Jarvis P. Use of a SPAD-502 meter to measure leaf chlorophyll concentration in Arabidopsis thaliana. Photosynth Res. 2011; 107(2):209-14.

\section{Publisher's Note}

Springer Nature remains neutral with regard to jurisdictional claims in published maps and institutional affiliations.

Ready to submit your research? Choose BMC and benefit from:

- fast, convenient online submission

- thorough peer review by experienced researchers in your field

- rapid publication on acceptance

- support for research data, including large and complex data types

- gold Open Access which fosters wider collaboration and increased citations

- maximum visibility for your research: over $100 \mathrm{M}$ website views per year

At $\mathrm{BMC}$, research is always in progress.

Learn more biomedcentral.com/submissions 